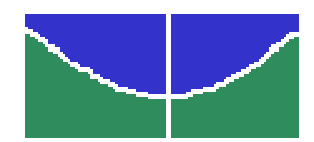

UNIVERSIDADE DE BRASÍLIA

FACULDADE DE ECONOMIA, ADMINISTRAÇÃo, CONTABILIDADE E CIÊNCIA DA INFORMAÇÃO E DOCUMENTAÇÃo (FACE)

Francisco Assis Lima

João Carlos nogueira de Castilho

\title{
ASPECTOS DA MANUTENÇÃO DOS EQUIPAMENTOS CIENTIFÍCOS DA UNIVERSIDADE DE BRASÍLIA
}


Francisco AsSis Lima

Jỗo Carlos Nogueira de Castilho

\section{ASPECTOS DA MANUTENÇÃO DOS EQUIPAMENTOS CIENTIFÍCOS DA UNIVERSIDADE DE BRASÍLIA}

Dissertação apresentada à Faculdade de Economia, Administração, Contabilidade e Ciência da Informação e Documentação (FACE), da Universidade de Brasília, como requisito ao grau de Especialistas em Desenvolvimento Gerencial.

Orientador: Doutor Marco Aurélio Gonçalves de Oliveira. 


\section{FICHA CATALOGRÁFICA}

LIMA, FRANCISCO ASSIS; CASTILHO, JOÃO CARLOS NOGUEIRA DE
Aspectos da Manutenção dos Equipamentos Científicos da Universidade de Brasília [Distrito Federal]2006.
x, 52 p., (FACE/UnB, Especialista, Desenvolvimento Gerencial, 2006).
Dissertação ao grau de Especialista - Universidade de Brasília. Faculdade de Economia, Administração, Contabilidade e Ciência
da Informação e Documentação.

\section{REFERÊNCIA BIBLIOGRÁFICA}

LIMA, FRANCISCO. ASSIS; CASTILHO, JOÃO CARLOS NOGUEIRA DE (2006). Aspectos da Manutenção dos Equipamentos Científicos da Universidade de Brasília. Dissertação de Especialização, Faculdade de Economia, Administração, Contabilidade e Ciência da Informação e Documentação, DF, 52 p.

\section{CESSÃO DE DIREITOS}

NOME DOS AUTORES: FRANCISCO ASSIS LIMA e JOÃO CARLOS NOGUEIRA DE CASTILHO

TÍTULO DA DISSERTAÇÃO: ASPECTOS DA MANUTENÇÃO DOS EQUIPAMENTOS CIENTÍFICOS DA UNIVERSIDADE DE BRASÍLIA.

GRAU/ANO: ESPECIALISTA/2006.

É concedida à Universidade de Brasília permissão para reproduzir cópias desta dissertação ao grau de especialista e para emprestar ou vender tais cópias somente para propósito acadêmico e científico. Os autores reservam outros direitos de publicação e nenhuma parte desta dissertação de especialização pode ser reproduzida sem autorização por escrito dos autores.

FRANCISCO ASSIS LIMA

JOÃO CARLOS NOGUEIRA DE CASTILHO

Campus UnB - Colina

Brasília/DF - Brasil

Brasília/DF - Brasil 
Dedicamos este trabalho a nossas esposas, nossos filhos e nossos pais, os grandes incentivadores. 


\section{AGRADECIMENTOS}

É sempre maravilhoso apresentar um trabalho e ter tantos a agradecer e a tantos homenagear. A relação completa certamente seria maior que o volume aqui apresentado. Com algum esforço vamos tentar expressar nossos sentimentos de forma resumida, embora seja difícil resumir sentimentos.

Aos nossos familiares são os mais dignos de todos, não deixando de lado nosso grande amigo, José Gonçalves de Matos, ex-diretor do Centro de Manutenção de Equipamentos Científicos da UnB que certamente merece um título mestre pelos ensinamentos sempre oportunos e inegável capacidade de transmitir sabedoria.

Ao maior incentivador, orientador, professor e amigo Marco Aurélio Gonçalves de Oliveira, o nosso grande apreço pela sua disponibilidade, e, pelas linhas de orientação que foram de um grande mestre, facilitando a elaboração deste trabalho, o nosso reconhecido e sentido agradecimento.

A Universidade de Brasília em especial a Faculdade de Economia, Administração, Contabilidade e Ciência da Informação e Documentação (FACE) e a todos da Secretaria de Recursos (SRH) que hoje nos concedem a oportunidade desta manifestação. Sentimos orgulhoso de participar deste conclave e uma felicidade imensa em ter recebido os ensinamentos dos diversos colegas, amigos, alunos e professores que por aqui passaram. $\mathrm{Na}$ impossibilidade de referir todos quantos de forma desinteressada, nos prestaram algum do seu esforço para que fosse possível a elaboração deste trabalho, apresentamos os nossos apreço e devido reconhecimento.

A Vera, secretária FACE, que de forma generosa cuidou dos compromissos e proporcionou os fatores que simplificaram a execução do trabalho, queremos prestar o devido reconhecimento.

Ao professor César Augusto Tibúcio, membro da banca, que não mediu esforços no apoio deste trabalho e pela forma pronta como aceitou o convite a participar desta 
jornada. O seu saber, os seus conselhos e o seu comprometimento com as propostas futuras merecem aqui o nosso grande apreço pela sua valiosa contribuição.

Cabe-me destacar Danielle, a sua colaboração nos ajudou a analisar e ultrapassar alguns fatores críticos de sucesso deste trabalho.

A Deus, a Graça de estar, simplesmente vivo, ter chegado até aqui e ter milhões de motivos para dizer Graças, Senhor! 


\section{RESUMO}

\section{Aspectos da Manutenção dos Equipamentos Científicos da Universidade de Brasília}

Esta pesquisa apresenta os aspectos da manutenção dos equipamentos científicos da Universidade de Brasília - UnB, buscando numa reflexão orientada a outras universidades brasileiras para acordarem para a idéia de que não basta o investimento na implementação do seu parque científico ou tecnológico, sendo fundamental que o tempo de utilização de todo o sistema seja o maior possível ao longo da vida útil. Principalmente pela escassez de recursos nos investimentos que cercam as universidades, é bastante comum se adquirir equipamentos e instalações, ponderando os aspectos de custos de investimento, mas negligenciando aspectos importantes para a manutenção, que dificultam os procedimentos em caso de defeito, cometendo-se o erro de não verificar a existência de meios humanos e materiais para a manutenção dos equipamentos.

A fundamentação obtida na literatura especializada define os principais conceitos de manutenção: corretiva, preventiva, preditiva, produtiva total e centrada na confiabilidade para, posteriormente, oferecer uma abordagem dos registros das ocorrências de manutenção entre os anos de 2003 e 2006, enfatizando as vantagens da manutenção preventiva planejada contra as ações corretivas, predominantemente executada pelo Centro de Manutenção de Equipamentos Científicos da UnB.

O grau de importância que o usuário considera em relação ao tempo de resposta e ao tempo total nas intervenções são confrontados com uma pesquisa de campo que pretende revelar o nível de satisfação do serviço prestado pelo Centro de Manutenção de Equipamentos Científicos da UnB que tem buscando um grau de confiabilidade que deve partir do princípio de que a manutenção se inicia na especificação do bem, no qual são considerados os aspectos que facilitam os procedimentos da manutenção.

Palavras-chaves:

Manutenção de equipamentos, satisfação do usuário, equipamentos científicos. 


\section{Lista de Tabelas}

Tabela 3.1 - Quadro de Pessoal do CME em junho de 2005.......................................... 26

Tabela 3.2 Equipamentos Registrados no SIAFI (2005) .............................................. 28

Tabela 3.1a - Ordens de Serviço Atendidas 2000 a 2005 ................................................ 32

Tabela 3.1b - Ordens de Serviço Atendidas 2006......................................................... 32

Tabela 4.1 - Indicadores do Crescimento da Universidade de Brasília ............................ 35

Tabela 4.2 - Intervenções de Manutenção janeiro de 2003 a junho de 2006..................... 37

Tabela 4.3 - Tempos Médios Gastos na Manutenção mais Representativos (julho de 2005 a junho de 2006).............................................................. 40 


\section{Lista de Figuras}

Figura 3.1 - Tempo Médio gasto na manutenção dos equipamentos.

Figura 4.1 - Evolução das Solicitações, Atendimentos e Baixa do Acervo Patrimonial..... 34

Figura 4.2 - Atendimentos por tipo de utilização............................................................. 36

Figura 4.3 - Quantidade de microcomputadores atendidos.......................................... 37

Figura 4.4 - Quantidade de monitores de vídeo e impressoras jato de tinta atendidos....... 38

Figura 4.5 - Quantidade de aparelhos de ar condicionado atendidos............................... 38

Figura 4.6 - Quantidade de microscópios binocular atendidos....................................... 39

Figura 4.7 - Quantidade de microscópio estereoscópico atendidos................................... 39

Figura 4.8 - Índice de Satisfação Geral...................................................................... 42

Figura 4.9 - Índice de Satisfação por Serviço Executado.............................................. 43

Figura 4.10 - Índice de satisfação com a comunicação..................................................... 43

Figura 4.11 - Importância que o usuário confere ao equipamento.................................... 44 
SUMÁRIO

1. INTRODUÇÃO __ 11

1.1 Identificação do Problema___ 12

1.2 Objetivos _ 13

1.2.1 Objetivo Geral __ 13

1.2.2 Objetivos Específicos __ 14

1.3 Justificativas __ 14

2. REFERENCIAL TEÓRICO___ 16

2.1 História da Manutenção___ 16

2.2 Os Conceitos de Manutenção __ 17

2.3 A Evolução da Manutenção___ 18

2.4 Tipos de Manutenção __ 20

2.4.1 Manutenção Corretiva ___ 21

2.4.2 Manutenção Preventiva ___ 22

2.4.3 Manutenção Preditiva _ 24

2.4.4 Manutenção Produtiva Total _ 26

2.4.5 Manutenção Centrada na Confiabilidade _ 28

3. METODOLOGIA — 32

3.1. Descrição do Centro de Manutenção de Equipamentos Científicos (CME) _ 32

3.1.1 Histórico — 32

3.1.2 Ferramentas Utilizadas na Gestão da Manutenção dos Equipamentos ___ 33

3.1.3 Estrutura Organizacional___ 35

3.1.4 O Parque de Equipamentos_ 37

3.1.5 Outros serviços prestados pelo CME _ 39

3.2 METODO UTILIZADO

3.2.1 Tipo de pesquisa __ 40

3.2.2 Amostra ou participantes da pesquisa ___ 41

3.2.3 Hipóteses 42

3.2.4 Instrumento _ 42

3.2.5 Procedimentos _ 43

4. Análise e Discussão ___ 44

4.1 Pesquisa documental ___ 44

5. Conclusões _

5.1 Conclusões Gerais _ 55

5.2 Sugestões _ 58

REFERENNCIAS

Apêndice__ 60 


\section{INTRODUÇÃO}

As técnicas administrativas que abordam a estratégia nas empresas vêm crescendo nos últimos anos, mas os aspectos da manutenção não têm sido suficientemente valorizados.

O nível de organização da manutenção nas universidades brasileiras reflete as particularidades do estágio de desenvolvimento industrial no Brasil. Parte dos investimentos realizados nas indústrias e também nas universidades é relativamente recente, contando com idades médias em torno de poucas dezenas de anos. Nos países onde a tecnologia eclodiu há mais tempo, o envelhecimento dos equipamentos e das instalações cedo chamou a atenção para a necessidade de racionalização das técnicas e dos procedimentos de manutenção.

Empresas de médio e grande porte da Europa e EUA dedicam grande esforço ao treinamento de pessoal e às técnicas de organização e gerenciamento da manutenção.

A idéia básica por trás do destaque conferido à manutenção é que não basta investir e implantar um sistema produtivo, científico ou tecnológico; é necessário que o tempo de utilização destes sistemas seja o maior possível ao longo da vida útil.

No caso particular da Universidade de Brasília, a organização do serviço de manutenção é insuficiente e reflete numa taxa de indisponibilidade exagerada dos equipamentos e instalações importantes para os laboratórios de ensino, pesquisa e de apoio administrativo, tendo como conseqüência a diminuição da capacidade produtiva da instituição e a insatisfação daqueles que dependem desse serviço. Isso tem se mostrado com o registro das ocorrências de reparo e as reclamações recebidas pelo setor de manutenção e aquelas encaminhadas à Administração Superior da Universidade.

$\mathrm{Na}$ aquisição dos equipamentos e instalações são ponderados os aspectos de custos de investimento, mas são negligenciados aspectos importantes para a manutenção, que dificultam os procedimentos em caso de defeito, cometendo-se o erro de não verificar a existência de meios humanos e materiais para a manutenção dos equipamentos.

Evidentemente, uma estrutura de manutenção organizada requer investimentos, esforços para a racionalização e a necessidade de atualização constante do pessoal técnico. Esses aspectos esbarram na visão administrativa interessada em resultados a curto prazo e solução de problemas imediatos, não avistando os grandes benefícios 
econômicos resultantes do aumento do tempo de utilização dos equipamentos e a redução dos prejuízos científicos e acadêmicos.

Em quase todo empreendimento é sabido que os custos com a mão-de-obra representam uma parcela significativa no custo total da organização. No caso da manutenção do parque de equipamentos da UnB, esta mão-de-obra é, em sua na maioria, realizada pela força produtiva do pessoal contratado indiretamente por empresas terceirizadas.

Desta forma, a credibilidade dos serviços prestados pelo Centro de Manutenção de Equipamentos Científicos (CME), da Universidade de Brasília, está diretamente ligada à qualidade dos profissionais contratados, suas habilidades, condições de trabalho, recursos empregados na manutenção e o contingente adequado à demanda de serviços.

A obsolescência acelerada dos equipamentos tem contribuído para o aumento do tempo médio em que os mesmos permanecem em manutenção, deixando os usuários cada vez mais insatisfeitos com a qualidade dos serviços prestados. Aliados a estes fatores tem-se notado a perda de credibilidade e a busca de soluções independentes que aumentam os custos do processo de recuperação dos equipamentos danificados.

Procurando reverter este cenário, o CME vem adotando medidas e alternativas à altura dos anseios almejados pelos Centros de Custos que dependem do serviço de manutenção, assim como a satisfação de todos os usuários.

\subsection{Identificação do Problema}

Duas grandes questões deveriam ter respostas voltadas aos problemas da manutenção e soluções definitivas. São elas:

1- Quanto custa a manutenção de um equipamento?

2- Qual o prejuízo de um equipamento parado com defeito?

As duas respostas têm pesos distintos dependendo da complexidade do sistema. A primeira questão tem resposta clara e imediata, refletindo o pensamento e ações abstratas da maioria dos envolvidos, enquanto na segunda, o resultado abrange diversos elementos e fatores que podem refletir em perdas irreparáveis ao ensino, à pesquisa e a todo o processo produtivo da Instituição. 
$\mathrm{Na}$ organização da manutenção empregada pelo CME os recursos computacionais já são utilizados desde 1994, com o armazenamento dos dados da manutenção, que compõem um histórico precioso relativo a cada equipamento mantido pelo Centro.

As questões relativas aos custos são de caráter relevante na análise da viabilidade do empreendimento na visão administrativa, podendo servir de indicadores para tomada de decisões e a definição de uma política de manutenção estratégica.

Em se tratando de uma Instituição de Ensino e Pesquisa com atuação nos diversos ramos científicos, os custos envolvidos na manutenção e na parada dos equipamentos têm pesos e valores agregados diferenciados, dependendo, fundamentalmente, da aplicação de cada equipamento. Ou seja, um mesmo equipamento pode ter relevante importância para uma aplicação cientifica, enquanto em outra pode não ser tão significativo.

Neste caso, o aspecto mais importante a ser abordado, diz respeito ao grau de satisfação que o usuário tem, depois de concluído o serviço. Esse elemento é deixado de lado pelo CME, embora possa refletir muito além dos custos envolvidos, pois somente o pesquisador poderá atribuir o valor científico de sua pesquisa e, no caso do ensino, cabe ao professor avaliar os prejuízos pela falta dos recursos em sala de aula e no apoio didático.

Uma pesquisa buscando identificar o grau de satisfação dos usuários do serviço de manutenção indicará, de forma indireta, um dos elementos mais importantes na avaliação dos gastos com a manutenção. Com os dados obtidos, poderá ser verificado se os recursos estão sendo aplicados de forma coerente e se os prejuízos ao ensino, à pesquisa e a todo o processo produtivo são altos ou baixos, podendo servir de parâmetro para a tomada de decisões e a implementação de melhorias na qualidade do serviço prestado pelo CME.

\subsection{Objetivos}

\subsubsection{Objetivo Geral}

O objetivo geral deste trabalho é avaliar os serviços prestados pelo CME, identificar o estágio em que se encontram em relação aos conceitos e tipos de manutenção, obter parâmetros quantitativos e qualitativos do atendimento prestado nos últimos anos, identificar o grau de satisfação dos usuários quanto aos serviços prestados e propor medidas 
que possibilitem o aprimoramento do atendimento, com mais qualidade, maior eficiência e menores custos.

\subsubsection{Objetivos Específicos}

A pesquisa mostrará a visão dos usuários sobre os serviços prestados pelo CME e terá como objetivos específicos os seguintes aspectos:

- Apresentar um breve histórico e a evolução da manutenção;

- Identificar os tipos e conceitos de manutenção;

- Apresentar um histórico da manutenção dos equipamentos na Universidade de Brasília;

- Obter dados sobre o atendimento prestado pelo CME nos últimos quatro anos;

- Identificar, no âmbito geral, o grau de satisfação do usuário diante dos serviços prestados pelo CME;

- Avaliar os tempos de resposta aos atendimentos de manutenção e o tempo de indisponibilidade de uso dos equipamentos;

- Avaliar a qualidade do serviço, agrupando por Centro de Custo de atendimento e pela especificidade dos equipamentos;

- Discutir a qualidade do serviço prestado pelo Centro de Manutenção; e

- Identificar quais indicadores de parâmetros influenciam a satisfação do usuário.

\subsection{Justificativas}

O grau de satisfação dos usuários dos serviços que o CME presta, tem sido desconsiderada na avaliação do desempenho que o Centro vem obtendo nos últimos anos.

Esta avaliação poderá oferecer elementos significativos na tomada de decisão para adoção de uma política estratégica de gestão da manutenção de equipamentos, em benefício do ensino e das pesquisas desenvolvidas na Instituição.

Este trabalho descreve aspectos que afetam a manutenção e está dividido em cinco capítulos, incluindo-se a introdução, que buscam comparar a satisfação do usuário com 
os resultados alcançados pela equipe de manutenção da Universidade de Brasília. No segundo capítulo predominam as referências de textos de literatura técnica que definem os conceitos de manutenção e servem de base para o entendimento das questões descritas nos capítulos seguintes.

O terceiro capítulo aborda a estrutura implementada na manutenção dos equipamentos, assim como a metodologia utilizada na pesquisa de campo. No capítulo seguinte encontram-se as pesquisas documentais, alcançadas de arquivos eletrônicos, para uma análise proposta e, finalizando o trabalho, o capítulo cinco apresenta as conclusões e sugestões a serem implementadas para o melhor desempenho do serviço de manutenção da instituição. 


\section{REFERENCIAL TEÓRICO}

Neste capítulo serão mostrados de forma sucinta a história da manutenção, seus conceitos e evolução ao longo dos anos. Serão também abordadas as metodologias e estratégias relativas aos diferentes tipos de manutenção utilizados, objetivando situar os serviços de manutenção prestados pelo CME no contexto teórico e avaliar a possibilidade de implementação de ações que permitam aprimorar a gestão da manutenção de equipamentos na UnB.

\subsection{História da Manutenção}

A revolução industrial ocorrida na primeira metade do século XIX trouxe a mecanização e com ela a necessidade de manter os equipamentos em condições satisfatórias de funcionamento. Até a década de 30 do século XX, entretanto, as manutenções não eram sistematizadas e na sua maioria realizadas pelas próprias equipes de produção. Consistiam basicamente em serviços de limpeza, lubrificação e reparos após a quebra (KARDEC; NASCIF, 2006).

A modernização das indústrias, ocorrida durante a segunda guerra mundial, fez com que a disponibilidade e confiabilidade dos equipamentos ganhassem importância. Passaram a ser estudados e desenvolvidos sistemas que não apenas corrigissem as falhas, mas que as evitassem. Os equipamentos perderam suas características de robustez e sobredimensionamento e passaram a exigir metodologias de manutenção. Por volta de 1950, em lugar da manutenção corretiva, realizada após a quebra e aplicada até então, começou-se a adotar uma nova metodologia, denominada Manutenção Preventiva, cuja característica é a substituição sistemática de peças ou itens, em intervalos fixos e predeterminados (SIQUEIRA, 2006).

A partir de 1970, com a utilização dos computadores, ocorreu o aprimoramento da manutenção preventiva, passando-se a selecionar e analisar dados sobre causa e efeito das falhas. Os métodos de trabalho foram revistos, buscando-se aumentar a eficiência das equipes de manutenção, reduzir os tempos de reparos e quantificar as peças sobressalentes. A metodologia decorrente da aplicação desses métodos foi denominada 
Manutenção Preditiva, que "busca identificar o final da vida útil dos componentes dos equipamentos com base na medição de sua degradação" (LUCATELLI, 2002, p.18).

O aumento da mecanização e da automação fez com que disponibilidade e confiabilidade se tornassem fatores cada vez mais importantes para a sobrevivência das empresas, num mercado globalizado e altamente competitivo. Tornou-se necessário não apenas rever os conceitos e procedimentos, mas também reduzir os custos da manutenção. Nos dias atuais, a manutenção procura, segundo Lucatelli (2002), contemplar a estratégia de gestão da conseqüência das falhas, ao invés da sua eliminação, ganhando importância a gestão da confiabilidade dos ativos físicos e o desenvolvimento metodológico.

\subsection{Os Conceitos de Manutenção}

A manutenção existe desde os primórdios da civilização, podendo ser identificada no ato de afiar um instrumento de caça ou substituir a corda de um arco. Com relação às máquinas e equipamentos, pode-se afirmar que a manutenção acompanha a sua evolução, desde as primeiras máquinas a vapor até os dias atuais.

Manter é conservar, sustentar. Qualquer componente físico que se deseje estar em condições de executar um trabalho para o qual foi projetado, dentro de um nível de desempenho esperado ou exigido, deve ser objeto de manutenção.

Segundo o dicionário Aurélio, manutenção significa "as medidas necessárias para a conservação ou permanência, de alguma coisa ou de uma situação" e ainda "os cuidados técnicos indispensáveis ao funcionamento regular e permanente de motores e máquinas" (FERREIRA, 1999, p. 1279).

Segundo Kardec e Nascif (2006), o conceito predominante da manutenção, até bem pouco tempo, era o de "restabelecer as condições originais dos equipamentos e sistemas". Hoje, o conceito é "garantir a disponibilidade da missão dos equipamentos e instalações de modo a atender um processo de produção ou de serviço, com confiabilidade, segurança, preservação do meio ambiente e custo adequados" (KARDEC; NASCIF, 2006, p. 22). 
A norma NBR 5462 (1994), define manutenção como:

a combinação de todas as ações técnicas e administrativas, incluindo as de supervisão, destinadas a manter ou recolocar um item em estado no qual possa desempenhar uma função requerida. Manutenção pode incluir como atividade a modificação de um item ou de um processo (ABNT 5462, 1994).

Para Lafraia (2002, p. 161), manutenção pode ser definida como o "conjunto de ações destinadas a manter ou recolocar um item num estado no qual pode executar sua função requerida".

Mirshawka e Olmedo (1993, p. 14 apud SILVA 1994, p. 13) definem manutenção como "o conjunto de atividades e recursos aplicados aos sistemas e equipamentos, visando garantir a consecução de sua função dentro de parâmetros de disponibilidade, de qualidade, de prazo, de custos e de vida útil adequados”. Nesta definição, de grande abrangência, a manutenção é caracterizada como um processo complexo e de fundamental importância para a produção e a qualidade dos produtos.

Lucatelli (2002) considera que a mudança de enfoque da função manutenção, dando importância não ao item, mas à função que ele possui, representa a "ruptura de um paradigma da manutenção" (LUCATELLI, 2002, p. 34). Nesse novo enfoque, a manutenção passa a buscar o reparo rápido e bem executado, reduzindo os serviços de emergência e introduzindo o conceito da mantenabilidade, definida como sendo a "facilidade com que um item é mantido ou recolocado no estado no qual pode executar suas funções requeridas" (MAIA Jr. 2003, p.11). Segundo o autor, este conceito, juntamente com a confiabilidade, passou a ter importância fundamental na disponibilidade dos ativos e conseqüentemente na receita das empresas. Já para Lafraia (2002), mantenabilidade tem um conceito mais amplo, sendo "uma característica de projeto que define a facilidade de manutenção, o tempo de manutenção, os custos e as funções que o item executa" (LAFRAIA, 2002, p. 161).

\subsection{A Evolução da Manutenção}

Cronologicamente podem ser identificadas três gerações para a manutenção de equipamentos. A primeira geração abrange o período anterior à Segunda Guerra Mundial, quando as indústrias eram pouco mecanizadas. As máquinas eram simples, robustas e de 
conserto fácil. O volume de produção, em razão da conjuntura econômica da época, não era prioritário, tornando desnecessária a manutenção sistematizada. Eram adotadas as formas mais simples ou rudimentares de manutenção, onde a atuação se dava após a ocorrência da falha. A esta manutenção não planejada, dá-se o nome de manutenção corretiva (MC) (KARDEC; NASCIF, 2006; SIQUEIRA, 2005).

A segunda geração da manutenção teve início durante a segunda guerra mundial, quando as pressões originadas da necessidade de produção em maior escala forçou a modernização e o aumento da complexidade das indústrias (KARDEC; NASCIF, 2006).

O esforço de industrialização pós-guerra fez disseminar as linhas de produção, provocando a dependência da sociedade em relação aos produtos e processos industriais. Em decorrência da velocidade em que novas indústrias foram implantadas, registrou-se a primeira onda de escassez de mão-de-obra especializada. Obter maior disponibilidade dos equipamentos, a baixo custo, tornou-se o objetivo básico das indústrias, motivando um esforço científico de pesquisa e desenvolvimento de técnicas de manutenção preventiva, com o objetivo de minimizar os impactos das falhas nos processos de produção. Desse esforço resultou o processo de revisão periódica dos equipamentos, complementando as atividades de limpeza e lubrificação e de manutenção corretiva, características da primeira geração da manutenção (SIQUEIRA, 2005). Surgiu assim a idéia de que as falhas poderiam ser evitadas se prevenidas, resultando no conceito da manutenção preventiva (MP), definida como a "substituição sistemática de itens com base em intervalos ou ciclos predeterminados" (LUCATELLI 2002, p. 36).

A terceira geração da manutenção foi consequiência da automação das indústrias, ocorrida na década de 1970. As técnicas anteriores mostraram-se incapazes de atender as exigências dos sistemas automatizados. $\mathrm{O}$ consumo em larga escala fez crescer a dependência dos processos industriais. Concomitantemente, o aumento de custos de mão-deobra e de capital fez com que os equipamentos passassem a ser dimensionados no limite da necessidade, com faixas operacionais mais estreitas, o que fez aumentar a importância da manutenção (SIQUEIRA, 2005). A adoção por alguns setores industriais de sistemas “just-intime", nos quais os estoques reduzidos de produtos inacabados implicavam na probabilidade de que pequenas interrupções poderiam interromper toda uma linha de produção é apontada como causa da busca por sistemas mais eficientes de manutenção (KARDEC; NASCIF, 2006; SIQUEIRA, 2005).

Ramirez, Caldas e Santos Jr. (2002), atribuem aos japoneses a introdução de saltos na qualidade da produção industrial, através da metodologia "just in time", dos círculos 
de qualidade e do controle de inventário, que trouxeram redução de custos, melhoria dos produtos através do monitoramento da produção por instrumentos microprocessados, melhorias na ergonomia, diminuição das falhas humanas por meio de treinamento e a adoção de projetos que minimizassem as conseqüências das falhas dos equipamentos.

A evolução da manutenção trouxe a tendência de que ela perdesse gradativamente o caráter corretivo, sendo adotada postura cada vez mais preventiva. Com a globalização, passou-se a exigir dos equipamentos maior eficiência e confiabilidade, não mais havendo espaço para sistemas produtivos marcados por falhas frequientes. A tendência atual é de que os equipamentos não só atendam a esses requisitos de eficiência e confiabilidade, mas também que os projetos levem em conta a facilidade de manutenção, tendo em vista serem os sistemas de produção cada vez mais complexos e interdependentes. Uma nova filosofia de gerenciamento da manutenção, utilizada de forma crescente, confirma esta tendência: é a Manutenção Baseada na Confiabilidade - MBC (Reality Centred Maintenance - RCM) também denominada Manutenção Centrada em Confiabilidade (MCC). A MCC tem como benefícios o aumento da vida útil dos equipamentos, a redução da quantidade de peças sobressalentes, a redução da quantidade de horas trabalhadas na manutenção programada e a diminuição dos custos da manutenção (RAMIREZ; CALDAS; SANTOS Jr., 2002).

$\mathrm{Na}$ terceira geração da manutenção, segundo Kardec e Nascif (2006), reforçou-se o conceito de uma manutenção preditiva, na qual "a interação entre as fases de implantação de um sistema (projeto, fabricação, instalação e manutenção) e a disponibilidade/confiabilidade torna-se mais evidente" (KARDEC; NASCIF, 2006, p. 5). Segundo os autores, "da correta realização de cada fase - projeto, fabricação, instalação, operação e manutenção - dependem a disponibilidade e confiabilidade do sistema" (KARDEC; NASCIF, 2006, p. 5).

\subsection{Tipos de Manutenção}

Os autores divergem quanto à classificação dos tipos de manutenção. Para Kardec e Nascif (2006), existem seis tipos diferentes de manutenção: Manutenção Corretiva não Planejada, Manutenção Corretiva Planejada, Manutenção Preventiva, Manutenção Preditiva, Manutenção Detectiva e Engenharia de Manutenção. Os diferentes tipos de manutenção, para os autores, podem ser considerados políticas de manutenção, "desde que 
sua aplicação seja resultado de uma definição gerencial ou política global da instalação, baseada em dados técnicos-econômicos" (KARDEC; NASCIF, 2006, p. 36). Destacam ainda a existência atual de ferramentas que têm no nome a palavra manutenção sem serem novos tipos de manutenção, mas ferramentas que permitem a aplicação dos seis tipos de manutenção citados. Dentre estas ferramentas, estão a Manutenção Produtiva Total, a Manutenção Centrada na Confiabilidade e a Manutenção Baseada na Confiabilidade (KARDEC; NASCIF, 2006, p. 36).

Outros autores, cuja classificação será adotada neste trabalho, agrupam todas as atividades de manutenção em duas categorias - manutenção corretiva e manutenção preventiva - sendo os demais tipos derivados e enquadrados como técnicas das categorias principais (LAFRAIA, 2002; RAMIREZ; CALDAS; SANTOS Jr., 2002; VIZONI apud LUCATELLI, 2002).

\subsubsection{Manutenção Corretiva}

A manutenção corretiva (MC), segundo Lafraia (2002), significa a adoção de "todas as ações para retornar um sistema do estado falho para o estado operacional ou disponível" (LAFRAIA 2002, p.173).

Kardec e Nascif (2006) definem a manutenção corretiva como a "atuação para correção da falha ou desempenho menor que o esperado" (KARDEC; NASCIF, 2006, p. 36).

Para Lucatelli (2002), a manutenção corretiva é o tipo de manutenção mais antigo e mais utilizado, sendo empregado em qualquer empresa que possua itens físicos, qualquer que seja o nível de planejamento da manutenção. A manutenção corretiva é caracterizada por ações reativas não-planejadas ou emergenciais, necessárias à restauração de um item a uma condição determinada (SMITH, 1993 apud LUCATELLI, 2002, p. 40).

Segundo a norma NBR 5462 (1994), manutenção corretiva é “a manutenção efetuada após a ocorrência de uma pane, destinada a recolocar um item em condições de executar uma função requerida" (ABNT 5462, 1994).

Para Maia Jr. (2003), a manutenção corretiva é toda manutenção para corrigir falhas em equipamentos, componentes, módulos ou sistemas, visando restabelecer sua função. 
Lucatelli (2002, p. 41) aponta como uma vantagem da manutenção corretiva a "não exigência de planejamento, enquanto estratégia". O autor ressalva, entretanto, que mesmo a manutenção corretiva exige um determinado nível de planejamento, no que diz respeito a ferramental, manuais, peças de reposição e treinamento.

De uma forma geral, a manutenção corretiva implica em custos altos, pois a falha inesperada pode acarretar em perdas de produção e queda de qualidade do produto. As paralisações são quase sempre mais demoradas e a insegurança exige estoques elevados de peças de reposição, com evidentes acréscimos nos custos de manutenção.

\subsubsection{Manutenção Preventiva}

A segunda guerra mundial provocou o crescimento da demanda por equipamentos, que se tornaram mais complexos e sofisticados. Ao mesmo tempo surgiu a necessidade de que não apenas os equipamentos, mas também os sistemas industriais, tivessem maior disponibilidade e confiabilidade, o que não poderia ser obtido com a prática da manutenção corretiva. O entendimento de que as falhas deveriam e poderiam ser evitadas trouxe a revisão de itens, que passou a considerar aspectos estatísticos de história das falhas e a ser realizada em intervalos de tempo determinados. Esse tipo de manutenção foi chamado de Manutenção Preventiva (MP) ou "manutenção baseada em intervalo/tempo" (GERAGHETY, 1996 apud LUCATELLI, 2002, p.41).

A essência da Manutenção Preventiva é a substituição de peças ou componentes antes que atinjam a idade em que passam a ter risco de quebra. A base científica da MP é o conhecimento estatístico da taxa de defeito das peças, equipamentos ou sistemas, ao longo do tempo.

Kardec e Nascif (2006, p. 39) definem a manutenção preventiva como a "atuação realizada de forma a reduzir ou evitar a falha ou a queda de desempenho, obedecendo a um plano previamente elaborado, baseado em intervalos de tempo definidos". A manutenção preventiva, contrariamente à manutenção corretiva, procura evitar, ou seja, prevenir. A adoção dessa política de manutenção é segundo os autores, imperativa em certos sistemas ou componentes, como por exemplo, a aviação, onde o fator segurança se sobrepõe aos demais. 
Nunes (2001 apud MAIA Jr., 2003, p. 13), define a MP como "todo serviço de manutenção programado para controle, conservação e restauração dos equipamentos, obras e instalações, a fim de mantê-los em condições satisfatórias de operação e evitar ocorrências que acarretem sua indisponibilidade".

A definição da NBR 5462 (1994) para a Manutenção Preventiva é "manutenção efetuada em intervalos predeterminados, ou de acordo com critérios prescritos, destinada a reduzir a probabilidade de falha ou a degradação do funcionamento de um item" (ABNT, 1994).

A programação de ações que orientem a substituição dos itens degradados em freqüências predeterminadas é condição para a implementação de um programa de manutenção preventiva. O primeiro passo para implantação desse programa é o cadastramento dos equipamentos, com informações sobre sua localização, identificação, regime de operação e tempo de utilização. A seguir, define-se a priorização dos equipamentos, com o objetivo de se obter maior eficiência, com otimização dos recursos disponíveis (LUCATELLI, 2002).

Um programa de manutenção preventiva bem implementado traz, segundo Ramirez, Caldas e Santos Jr. (2002), os seguintes benefícios:

- Redução do tempo de inatividade dos equipamentos devido a falha;

- Redução dos custos operacionais;

- Aumento de produtividade; e

- Correção de problemas operacionais antes que eles se agravem e se tornem mais difíceis de resolver.

São apontados, no entanto, alguns inconvenientes dos programas de manutenção preventiva (RAMIREZ; CALDAS; SANTOS Jr., 2002):

- Investimento financeiro alto, em recursos materiais e humanos;

- Gerenciamento mais complicado em relação à manutenção corretiva; e

- Os equipamentos ficam fora de uso, durante os procedimentos de manutenção.

Na visão de Kardec e Nascif (2006), a conveniência da adoção da manutenção preventiva está ligada à simplicidade da reposição, ao alto custo das falhas e à 
implicação das falhas na segurança pessoal e operacional. A manutenção preventiva possibilita o conhecimento prévio das ações, boa condição de gerenciamento e a previsão de consumo de materiais. Por outro lado, implica na retirada do equipamento ou sistema de operação para a realização dos serviços programados, gerando questionamentos a sua adoção em sistemas onde não haja fatores suficientemente fortes para justificar a sua implementação. Outro fator negativo com relação à manutenção preventiva seria a possibilidade de introdução de defeitos não existentes, em razão de falha humana, defeitos em peças sobressalentes, contaminações em sistemas de lubrificação e danos durante as partidas e paradas (KARDEC; NASCIF, 2006, p. 41).

\subsubsection{Manutenção Preditiva}

A Manutenção Preditiva pode ser definida, segundo Kardec e Nascif (2006, p. 41), como "a atuação realizada com base em modificação de parâmetro de condição ou desempenho, cujo acompanhamento obedece a uma sistemática". Seu objetivo é o de prevenir falhas nos equipamentos ou sistemas mediante o acompanhamento de diversos parâmetros e possibilitando assim, que o equipamento opere continuamente, pelo maior tempo possível. A manutenção preditiva privilegia a disponibilidade, pois as medições e verificações são efetuadas com o equipamento em funcionamento. A decisão de intervenção é tomada quando a degradação se aproxima de um limite previamente estabelecido (KARDEC; NASCIF, 2006, p. 42).

Para Lucatelli (2002), a manutenção preditiva é baseada na monitoração dos 'sinais vitais' do item, ou seja, associa o surgimento da manutenção preditiva ao aperfeiçoamento da informática.

Segundo Monchy (1989 apud MAIA Jr., 2003, p.15), a manutenção preditiva pode ser considerada uma forma evoluída da manutenção preventiva. Com o aperfeiçoamento da informática, tornou-se possível estabelecer previsão de diagnósticos de falhas possíveis, através da análise de certos parâmetros dos sistemas produtivos.

Geraghety (1996 apud LUCATELLI, 2002, p.44), cita estudo desenvolvido por Nowlamn e Heap, cujas conclusões levaram à busca de novas alternativas à manutenção preventiva, uma vez que esta, em razão de custos altos e baixa disponibilidade dos equipamentos, já não satisfazia a muitas empresas. As conclusões do estudo foram de que 
num equipamento complexo, as revisões programadas têm pouco efeito na confiabilidade total, ressalvada a existência de um modo de falha dominante e que para muitos equipamentos não há forma efetiva de manutenção programada.

A partir da constatação dessas condições, surgiu a manutenção preditiva, baseada na monitoração dos sinais vitais do item. Através do acompanhamento sistemático das variáveis que indicam o desempenho dos equipamentos, define-se a necessidade da intervenção (XAVIER, 2000; BRANCO FILHO, 2000 apud LUCATELLI, 2002, p.44).

Segundo Maia Jr. (2003) busca-se, num sistema de manutenção preditiva, realizar a intervenção somente quando necessária, planejando-se com antecedência as paradas dos equipamentos e minimizando os custos das paradas imprevistas. Para as inspeções necessárias à manutenção preditiva, utilizam-se não apenas instrumentos, mas também os sentidos humanos, objetivando comparar valores com os parâmetros conhecidos, de forma a se obter a informação de quando os problemas potenciais irão acontecer e então tentar evitálos. Nessa visão, a vida útil do equipamento é maximizada pela redução do índice de probabilidade da falha, sendo as ações mais freqüentes pensadas e planejadas de forma prévia, com base em diagnósticos. (MAIA Jr., 2003, p. 15).

Kardec e Nascif (2006), consideram que a manutenção preditiva, uma vez decidida, passa a ser uma manutenção corretiva planejada e que as condições básicas para implementá-la são:

- Possibilidade de monitoramento e medição do equipamento ou sistema;

- Viabilidade de custos;

- Possibilidade de monitoramento das falhas e acompanhamento de sua progressão; e

- Estabelecimento de programa sistematizado de acompanhamento, análise e diagnóstico.

A adoção de política de manutenção preventiva deve passar pela análise dos seguintes fatores (KARDEC; NASCIF, 2006, p. 42):

- Segurança pessoal e operacional;

- Redução de custos, diminuindo as intervenções desnecessárias; e 
- Tempo máximo em que os equipamentos permanecem em operação, com segurança.

Outra condição considerada fundamental para a aplicação da manutenção preditiva é a qualificação da mão-de-obra responsável pela análise e diagnóstico, para que as ações de intervenção tenham qualidade equivalente aos dados registrados (KARDEC; NASCIF, 2006).

Segundo Mobley (1998 apud LUCATELLI, 2002), a manutenção preditiva visa fundamentalmente: prever antecipadamente a necessidade de manutenção, permitindo a programação das atividades; eliminar desmontagens desnecessárias; aumentar a vida útil e a disponibilidade dos equipamentos; reduzir as ações não planejadas; impedir os aumentos dos danos e aumentar a confiabilidade dos equipamentos. Para o autor, a manutenção preditiva, apesar de sua eficácia, não pode ser empregada de forma generalizada, por apresentar alguns pontos desfavoráveis. Esses pontos são: exigência de grande volume de recursos iniciais, tanto materiais como humanos; mão de obra muito qualificada e treinada; restrição para aplicação em sistemas industriais complexos (monitoração possível restrita a apenas $20 \%$ dos modos de falha existentes, aproximadamente).

\subsubsection{Manutenção Produtiva Total}

A Manutenção Produtiva Total teve origem nos programas de qualidade surgidos após a segunda guerra mundial, em face da necessidade de produção em massa, de forma a suprir a demanda, numa conjuntura em que muitas nações industriais tinham sido destruídas pela guerra.

Em 1950, W. Eduards Deming foi ao Japão para colaborar na realização de um censo populacional e proferiu palestras a empresários japoneses sobre Controle Estatístico da Qualidade. A importância de Deming para a indústria japonesa foi tamanha que ele fico conhecido como o "fundador da terceira onda da revolução industrial" (MIRANDA, 1994). Foi graças ao sucesso dos programas de Qualidade Total que a indústria japonesa superou a crise do petróleo da década de 1970, passando seu modelo a ser seguido pelos países do ocidente. 
Em decorrência dos programas de qualidade, as empresas começaram a buscar sistemas de manutenção que viabilizassem maior disponibilidade e confiabilidade de suas máquinas. Inicialmente, as manutenções seguiam programações pré-determinadas, desconsiderando a real necessidade de intervenções e ocorriam sem a participação dos operadores das máquinas. Em muitos casos, a manutenção era desnecessária, acarretando em novos defeitos e aumento de custos. Como uma das características dos programas de qualidade era o controle dos defeitos na sua origem, os operadores passaram a participar e apontar os defeitos de suas máquinas, para evitar falhas futuras. Surgiu assim, em meados da década de 1970, a Manutenção Produtiva Total (TPM), cuja sistematização se deu no Japão, pela Divisão de Manutenção da Nippon Denso, da Toyota (TAVARES, 1996 apud LUCATELLI, 2002).

Para Maia Jr. (2002), a TPM significa a participação dos operadores nos esforços de manutenção preventiva e corretiva, criando-se uma mentalidade de autogerenciamento do seu local de trabalho.

Kardec e Nascif (2006) consideram que a TPM deriva da manutenção preventiva, sendo o resultado de sua evolução. Vários fatores econômico-sociais ocorridos na década de 1970 obrigaram as empresas, para se tornarem mais competitivas, a eliminar desperdícios, buscar o melhor desempenho dos equipamentos, reduzir as interrupções e paradas dos equipamentos, redefinir o perfil de conhecimentos e habilidades dos empregados e mudar sistemáticas de trabalho. Para tal, foram utilizados os grupos de trabalho conhecidos como Círculos de Controle de Qualidade (CQD) e Zero Defeito (ZD) que disseminaram os conceitos base da TPM: exercício do autocontrole; conhecimento da máquina pelo operador; integração homem, máquina e empresa; responsabilidade de todos com a manutenção dos meios de produção (KARDEC; NASCIF, 2006, p. 181).

Fleming e França (1997 apud LUCATELLI, 2003, p. 46), definem a TPM como "um modo de vida no trabalho objetivando a eliminação das perdas crônicas e a identificação dos potenciais de falhas, por meio da manutenção autônoma e planejada".

A implementação da TPM é fundamentada em ações, conhecidas como os oito pilares de sustentação da metodologia. Os oito pilares são:

1. Melhoria focada, que consiste em focar a melhoria do negócio, buscando reduzir os problemas para melhorar o desempenho; 
2. Manutenção autônoma, implicando no autogerenciamento e controle, liberdade de ação, cumprimento de padrões, conscientização da filosofia da TPM;

3. Manutenção planejada, com a aplicação de treinamento em técnicas de planejamento (software), utilização de sistema mecanizado de planejamento da programação diária e de paradas;

4. Educação e treinamento, ampliando a capacitação técnica, gerencial e comportamental do pessoal de operação e manutenção;

5. Controle inicial, buscando a eliminação das falhas na fase inicial, com a implantação de sistemas de monitoramento;

6. Manutenção da qualidade, com a implantação de programa de defeito zero;

7. TPM Office - estabelecimento de programa TPM nas áreas administrativas; e

8. Segurança, com o estabelecimento de sistema de saúde, segurança e meio ambiente (KARDEC; NASCIF, 2006, p. 185-186).

O objetivo principal dessas ações é o aumento da eficiência dos equipamentos, com redução dos custos operacionais. A atuação não se dá apenas no reparo, mas também junto ao operador e na gestão do equipamento, visando eliminar todas as perdas (KARDEC; NASCIF, 1999 apud Lucatelli, 2002, p.48).

Identifica-se ainda, com a implantação da TPM, ganhos relativos à participação de todos os envolvidos no processo, maior autoconfiança, mais atenção ao trabalho, maior espírito de equipe, menos rotatividade de pessoal (NAGAO, 2001 apud LUCATELLI, 2002).

\subsubsection{Manutenção Centrada na Confiabilidade}

A origem da Manutenção Centrada na Confiabilidade (MCC) está relacionada com os processos tecnológicos e sociais decorrentes da segunda guerra mundial. No campo tecnológico, situam-se as pesquisas da indústria bélica norte-americana, seguidas pela automação industrial em escala mundial, o desenvolvimento da informática e das 
telecomunicações. No campo social, identifica-se a dependência da sociedade contemporânea em relação aos métodos automáticos de produção, que atingiu níveis capazes de afetar o meio ambiente e a segurança física dos seres humanos. Com a evolução da consciência sobre a importância da preservação dos recursos naturais, passou-se a exigir que os projetos e sistemas de manutenção dos meios de produção atendam aos anseios e necessidades da sociedade e sejam estruturados de forma transparente (SIQUEIRA, 2005).

A necessidade de certificação da linha de aviões Boeing 747 pela Federal Aviation Administration (FAA), órgão americano responsável pela regulamentação de linhas aéreas é tida como o evento a que se atribui o surgimento da MCC. O Boeing 747 apresentou níveis de automação extremamente elevados em comparação às aeronaves então existentes e o uso das metodologias tradicionais de manutenção não atenderia às exigências das autoridades norte-americanas. Estudos realizados por grupo composto pelos engenheiros Bill Mentzer, F. Stanley Nowlan e Howard F. Heap, resultaram em relatório, considerado hoje um clássico da literatura sobre manutenção, que introduziu os conceitos de uma nova metodologia, denominada posteriormente Reliability-Centred Maintenance (RMC), ou Manutenção Centrada na Confiabilidade (MCC) (SIQUEIRA, 2005).

O programa de manutenção para o avião Boeing 747 em 1967, segundo Maia Jr. (2003), foi denominado Maintenance Steering Group (MGS-1). A eficácia do programa levou ao seu aperfeiçoamento e uso para outras aeronaves, inclusive militares, dando origem ao MGS-2. O programa MGS-3 surgiu nos anos 70, para o Departamento de Defesa Americano. Atualmente, todos os planos de manutenção das aeronaves que usam o espaço aéreo norte-americano devem ser embasados no MGS-3.

Os benefícios da MCC foram percebidos e a metodologia rapidamente aplicada em diversos setores, como na manutenção de submarinos nucleares, na indústria elétrica americana e em usinas elétricas nucleares, expandindo-se a seguir para a indústria elétrica mundial, construção civil, indústria química, siderurgia, etc. A generalidade dos conceitos e técnicas da MCC são aplicáveis hoje, segundo Siqueira (2005), a qualquer sistema, independente da tecnologia.

Segundo Lafraia (2002), o objetivo da manutenção na ótica da MCC é assegurar que um sistema ou item continue a preencher as suas funções desejadas. Na MCC, os objetivos da manutenção são definidos pelas funções e padrões de desempenho requeridos para qualquer item no seu contexto operacional e sua aplicação é um processo contínuo, devendo ser reavaliada na medida em que a experiência operacional é acumulada. Assim, a aplicação continuada da MCC possibilita a obtenção de dados que permitem reavaliar a 
freqüência da manutenção em bases realistas. Um resumo dos benefícios da MCC para os equipamentos e sistemas, conforme Lafraia (2002, p. 240), é:

- Redução na carga de trabalho de manutenção preventiva;

- Aumento da disponibilidade;

- Aumento da vida útil;

- Redução da quantidade de peças sobressalentes;

- Especialização de pessoal em planejamento de manutenção;

- Rastreamento das decisões; e

- Motivação para o trabalho em equipe.

Smith (1993 apud LUCATELLI, 2002, p. 51), define quatro objetivos principais propostos pela MCC, que são:

- Preservação da função do sistema;

- Identificação das falhas funcionais e de seus modos de falha;

- Classificação e priorização das falhas funcionais analisando os modos de falha; e

- Seleção das atividades de manutenção preventiva segundo a viabilidade técnica e a eficiência, para a preservação das funções do sistema.

Moubray (2000 apud MAIA Jr., 2003) define a MCC como um processo usado para orientar as ações que assegurem o desempenho de qualquer ativo físico, em conformidade com o que os usuários esperam dele no contexto operacional presente, sendo uma metodologia para selecionar e desenvolver sistemas de manutenção com base em critérios operacionais, econômicos e de segurança.

Para Siqueira (2005), a filosofia central da MCC é que uma estratégia de manutenção concentra-se em evitar ou reduzir as consequiências significativas das falhas, priorizando o atendimento às necessidades do processo, em detrimento das necessidades individuais de itens. A forma efetiva de melhor combater as conseqüências das falhas é o estudo dos modos de falha. As conseqüências significantes são definidas assim, como as que afetam um dos seguintes aspectos do ambiente operacional: segurança de pessoal; qualidade 
do meio ambiente; operação do processo; e a economia do processo (SIQUEIRA, 2005, p. 17).

As metodologias MCC e TPM como instrumento de gerenciamento da manutenção podem ser vistas como complementares, na visão de alguns autores. Segundo Azevedo (2000 apud LUCATELLI 2002, p. 53), "a MCC possui características de pertinência - determina o que deve ser feito e por que deve ser feito", enquanto a TPM "tem características de logística - determinando como deve ser feito".

Fleming (2000 apud LUCATELLI, 2002, p. 53), diz que "em razão da realidade do mercado atual, o qual impõe um nível de competitividade tal que a sobrevivência das empresas depende de inovações criativas, a implantação conjunta da TPM e MCC pode proporcionar um salto inovador em qualidade e produtividade por conjugar sem prejuízo os benefícios de ambas". 


\section{METODOLOGIA}

Este capítulo tem por objetivo abordar os aspectos da manutenção dos equipamentos da Universidade de Brasília, a estrutura organizacional do setor competente e o modelo de gerenciamento, bem como a metodologia utilizada na avaliação do grau de satisfação dos usuários deste serviço especializado, levando em consideração os conceitos apresentados no capítulo anterior.

\subsection{Descrição do Centro de Manutenção de Equipamentos Científicos (CME)}

A análise do serviço de manutenção de equipamentos, no contexto da Universidade de Brasília, deve levar em conta a dinâmica de evolução que a própria Universidade assumiu ao expandir a esfera do ensino, da pesquisa e da extensão, provocando, em conseqüência disso, um enorme descompasso entre a quantidade de equipamentos adquiridos e os recursos aplicados na preservação desse patrimônio.

Os registros de ingresso no patrimônio da Universidade de Brasília mostram que a evolução tecnológica trouxe equipamentos diversos e de variadas tecnologias, sem o controle direto da Administração Central, canalizando o problema da conservação ao CME, o qual assumiu e forneceu um quadro abrangente no contexto atual, porém deficitário pela limitação de seus recursos.

\subsubsection{Histórico}

Até 1987, a manutenção de equipamentos da Universidade de Brasília era realizada pela Oficina Técnica de Manutenção (OTM), subordinada ao Serviço de Patrimônio Mobiliário. O crescimento da quantidade de equipamentos, sua diversificação e a falta de autonomia financeira e administrativa, levaram à necessidade de revitalização dos serviços, consubstanciada na criação do Centro de Manutenção de Equipamentos Científicos (CME) pelo Ato da Reitoria ${ }^{\circ}$ 550/87 de 30.10.87. Ao CME foram atribuídas a responsabilidade de promover, com qualidade, a manutenção e o reparo dos equipamentos da Universidade, bem como introduzir novos conceitos, metodologias e técnicas que viessem a reduzir as paradas dos equipamentos, visando a redução de custos, a satisfação dos usuários e a viabilização das 
atividades de ensino e de pesquisa. Para cumprir tais atribuições, o CME foi dotado de autonomia administrativa e financeira, assegurada pelo Ato da Reitoria $\mathrm{N}^{\circ}$ 549/87.

Os serviços prestados pelo CME a partir dessa reformulação, chegaram a ser referência para outras Instituições Federais de Ensino Superior. No entanto, o crescimento do número de alunos, dos cursos de graduação e pós-graduação, dos laboratórios, da quantidade de equipamentos, especialmente os de informática, climatização e ópticos, sem a necessária contrapartida de investimentos em infra-estrutura e recursos humanos, levaram a uma gradativa perda de eficiência, manifestada pela insatisfação dos usuários quanto aos serviços prestados, tanto em termos quantitativos quanto qualitativos, que atingiu o seu ponto máximo negativo no ano de 1993.

A partir de 2004, quando começaram a ser introduzidos em alguns grupos de equipamentos, serviços de manutenção preventiva e aplicados novos conceitos na gestão dos recursos humanos disponíveis, observou-se o crescimento do número de atendimentos e em consequiência a diminuição do número de reclamações dos usuários. A permanência dos investimentos poderá levar o CME a readquirir a confiança dos demais Centros de Custo da Universidade e apresentar soluções independentes que facilitarão ainda mais o seu crescimento, prestando um serviço de qualidade, compatível com os anseios e necessidades da comunidade universitária.

\subsubsection{Ferramentas Utilizadas na Gestão da Manutenção dos Equipamentos}

O gerenciamento da manutenção do parque de equipamentos da UnB é informatizado, permitindo a todos os usuários solicitar e acompanhar os reparos nos equipamentos ou a programação de manutenção preventiva de todos os equipamentos cadastrados no Sistema de Informações Patrimoniais (SIPAT), sejam eles da UnB ou de outras Instituições.

Para facilitar o gerenciamento da manutenção, o CME utiliza informações básicas, a partir do ingresso do equipamento e dos registros das ocorrências, envolvendo fornecedores e a própria equipe do $\mathrm{CME}$, mesmo que esses equipamentos sejam oriundos de convênios e comodatos.

As principais funções que envolvem a atividade da manutenção, com base nos registros cronológicos, são: 
- Acompanhamento do equipamento no período de garantia - avaliação do desempenho do equipamento e do fornecedor;

- Cadastro - Fornecedores e serviços;

- Histórico da manutenção ou procedimento da manutenção — registro de intervenções, constando aplicação de material, pessoal envolvido e tempo gasto; $\mathrm{e}$

- Atualização de dados técnicos — modificações e atualizações de características do equipamento, garantindo sua integridade.

A clientela do CME é denominada de Usuário, dividindo-se em duas categorias: Usuário Interno e Usuário Externo. Os Usuários Internos são todos os membros da comunidade universitária (alunos, docentes e outros colaboradores) que fazem uso direto dos equipamentos cadastrados no SIPAT; os Usuários Externos são entidades não-ligadas à UnB empresas públicas e privadas ou pessoa física, que venham a utilizar os serviços do Centro.

O fator que mais interessa aos usuários, sejam eles internos ou externos, é sem dúvida o tempo que o equipamento ficará indisponível durante a manutenção. O tempo, para efeito da manutenção, também é classificado em duas denominações: Tempo de Resposta, que consiste no intervalo entre o registro da solicitação de reparo e o primeiro atendimento no local onde o equipamento está instalado e Tempo Total de Manutenção, caracterizado pelo tempo total em que o equipamento fica indisponível para utilização, ou seja, o tempo decorrente entre a solicitação e a conclusão do serviço.

Embora os Tempos Médios de Resposta e o Tempo Total de Manutenção sejam elevados, a Figura 3.1 a seguir mostra que o Tempo Médio Total de Manutenção, incluindo o Tempo de Resposta, tem diminuído a partir de 2004.

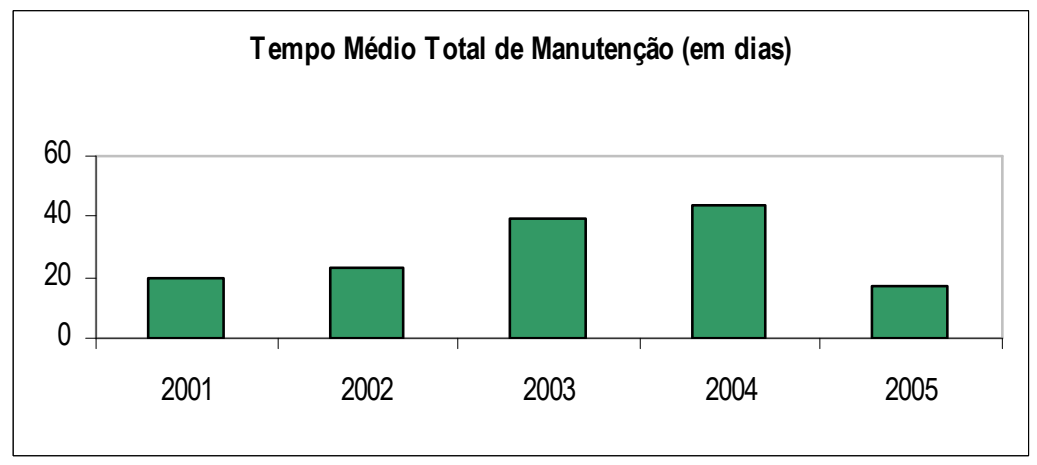

Fonte: Relatório de Atividades CME: 2005

Figura 3.1 - Tempo Médio gasto na manutenção dos equipamentos. 
Para atender os casos especiais, quando a falha num equipamento compromete a produção da unidade e o CME é informado, os tempos de resposta e de manutenção são acelerados com o objetivo de evitar maiores danos aos trabalhos em curso, principalmente as pesquisas em desenvolvimento.

As ferramentas e procedimentos empregados pelo CME na manutenção dos equipamentos da UnB, têm como propósito a redução de custos, a satisfação do usuário e a viabilização das atividades de ensino e pesquisa, permitindo que professores e pesquisadores dediquem seu tempo às suas atividades fins.

\subsubsection{Estrutura Organizacional}

$\mathrm{Na}$ estrutura organizacional do CME estão compreendidas quatro seções especializadas: Seção de Apoio e Logística, Seção de Eletrônica e Informática, Seção de Eletromecânica e Seção de Mecânica.

A Seção de Apoio e Logística compreende dois setores: Setor de Material e Setor de Transporte e Movimentação, que têm como atribuições o controle de material de consumo (partes e peças de reposição) e permanente (equipamentos em manutenção), e o cuidado com infra-estrutura e suporte.

A Seção de Eletrônica e Informática compreende dois setores: Setor de Eletrônica e o Setor de Informática, que têm como atribuições a manutenção, reparo e instalação dos equipamentos eletrônicos e de informática.

A Seção de Eletromecânica compreende três setores: Setor de Óptica, Setor de Eletrotécnica e Setor de Mecânica Fina, cujas atribuições são a manutenção, reparo e instalação de equipamentos ópticos e mecânica fina (microscópio, câmaras fotográficas, projetores e outros equipamentos de precisão) e eletrotécnicos (equipamentos elétricos, de aquecimento e de movimento).

A Seção de Mecânica compreende dois setores: Setor de Refrigeração e Setor de Mecânica Geral, que têm como atribuições a manutenção, reparo e instalação de equipamentos de refrigeração e conforto ambiental, bem como a construção de partes e peças mecânicas.

Na ocasião em que este estudo foi realizado, o quadro de pessoal registrava a composição da Tabela 3.1 . 


\begin{tabular}{|l|c|c|c|c|c|}
\hline \multicolumn{7}{|c|}{ Tabela 3.1 - Quadro de Pessoal do CME em junho de 2005 } \\
\hline Setores & $\begin{array}{c}\text { Permanentes } \\
\text { da UnB }\end{array}$ & Terceirizados & $\begin{array}{c}\text { Prestadores } \\
\text { de Serviço }\end{array}$ & Estagiários & Total \\
\hline Eletrônica e Informática & 4 & 9 & 1 & 1 & 15 \\
\hline Ótica & 1 & 1 & 0 & 0 & 2 \\
\hline Eletrotécnica & 5 & 5 & 0 & 0 & 10 \\
\hline Mecânica & 1 & 6 & 0 & 0 & 7 \\
\hline Apoio e Logística & 0 & 3 & 3 & 0 & 6 \\
\hline Secretaria Executiva & 1 & 0 & 1 & 3 & 5 \\
\hline Direção e Vice-Direção & 1 & 0 & 0 & 0 & 1 \\
\hline \multicolumn{1}{|c|}{ Total } & 13 & 24 & 5 & 4 & 46 \\
\hline \hline
\end{tabular}

A diversidade de vínculos empregatícios no quadro de pessoal tem dificultado a gestão das pessoas, no que se refere às diferenças de salário, atribuições, normas específicas a cada grupo, direitos e deveres.

Apesar da reestruturação interna, implementada a partir de 2003, com o objetivo de garantir o crescente atendimento das solicitações, o quadro de pessoal se encontra defasado, quando comparado a períodos anteriores, onde a disponibilidade de pessoal era maior enquanto o número de equipamentos reparados era menor.

Na criação do CME tinha-se como objetivo a manutenção dos equipamentos científicos - de ensino e de pesquisa. Desde então, a falta de uma estrutura própria para atender os equipamentos de apoio administrativo fez com que o atendimento fosse estendido a outros equipamentos, sobrecarregando a sua capacidade de atendimento.

O crescimento do CME em termos da quantidade e da qualidade do atendimento prestado é fortemente limitado pelo espaço físico disponível. Enquanto se observa o crescimento da Universidade quanto ao número de cursos, alunos, laboratórios, e espaço físico total, a área ocupada pelo Centro permanece a mesma desde 1987. Estudos realizados pelo Centro de Planejamento Oscar Niemeyer (CEPLAN) indicam a necessidade de $2.500 \mathrm{~m}^{2}$ contra os $624 \mathrm{~m}^{2}$ utilizados na ocasião deste trabalho.

A limitação e inadequação do espaço físico impedem o atendimento dos equipamentos de grande porte, limitando o estoque de peças de reposição, o contingente de pessoal, a criação de novas oficinas e a aquisição de outros equipamentos de testes e medições, bem como a adoção de procedimentos de certificação e aferição de equipamentos de laboratório. 


\subsubsection{O Parque de Equipamentos}

O parque de equipamentos da UnB é bastante diversificado, o que faz do processo de manutenção um permanente desafio. A diversificação, complexidade e quantidade de equipamentos demandam elevado estoque de peças de reposição, espaço físico, qualificação permanente dos técnicos, meios de transporte específicos e, sobretudo, um sistema de gerenciamento e comunicação que esteja em constante evolução, pronto a atender às necessidades emergentes. Há ainda, diversos equipamentos importados, que requerem na maioria das vezes, serviços especializados.

O crescimento contínuo da Universidade, assim como do parque de equipamentos, exige recursos financeiros e humanos aplicados na estrutura da manutenção em quantidades compatíveis com as necessidades e demandas dos usuários.

Além da preocupação com a produção, a manutenção de equipamentos deve estar focada nos motivos que melhor definem a razão de sua existência, quais sejam: a prevenção, a diagnose, a capacitação de pessoal, a educação dos usuários dos equipamentos e da comunidade em geral.

Para promover mudanças com este enfoque, é necessário que na dinâmica do trabalho haja uma nova abordagem de soluções, interagindo com toda a comunidade universitária, não só reparando e fazendo a manutenção dos equipamentos em si, como também prevenindo, informando, esclarecendo e criticando as atitudes e posturas não condizentes com a gestão do patrimônio público.

O número de equipamentos existentes na $\mathrm{UnB}$, segundo os dados obtidos no acervo de patrimônio, obedecendo a classificação do SIAFI (2005), supera a marca de 150 mil unidades conforme a Tabela 3.2. 


\begin{tabular}{|r|l|r|}
\hline \multicolumn{3}{|c|}{ Tabela 3.2 Equipamentos Registrados no SIAFI (2005) } \\
\hline \multicolumn{1}{|c|}{ Denominação } & Registros \\
\hline 142120400 & Aparelhos de Medição e Orientação & 4.787 \\
\hline 142120600 & Aparelhos e Equipamentos de Comunicação & 9.000 \\
\hline 142121000 & Aparelhos e Equipamentos para Esportes e Diversões & 230 \\
\hline 142121200 & Aparelhos e Utensílios Domésticos & 209 \\
\hline 142120800 & Aparelhos, Equipamentos, Utensílios Med. Odont. Lab. Hospital & 21.972 \\
\hline 142122200 & Equipamentos de Manobra e Patrulhamento & 10 \\
\hline 142123500 & Equipamentos de Processamento de Dados & 58.713 \\
\hline 142122400 & Equipamentos de proteção, Segurança e Socorro & 652 \\
\hline 142123900 & Equipamentos Hidráulicos e Elétricos & 282 \\
\hline 142123300 & Equipamentos de Áudio, Vídeo e Foto & 12.571 \\
\hline 142122800 & Máquinas e Equipamentos de Natureza Industrial & 152 \\
\hline 142123000 & Máquinas e Equipamentos Energéticos & 12.421 \\
\hline 142123200 & Máquinas e Equipamentos Gráficos & 634 \\
\hline 142123800 & Máquinas, ferramentas e Utensílios de Oficina & 2.763 \\
\hline 142123600 & Máquinas, Instalações e Utensílios de Escritório & 16.139 \\
\hline 142123400 & Máquinas, Utensílios e Equipamentos Diversos & 11.703 \\
\hline & & 152.238 \\
\hline
\end{tabular}

Fonte: Sistema de Patrimônio - UnB

A diversidade impõe a necessidade de mão-de-obra especializada e adequada a cada tipo de equipamento, com utilização de instrumentos e ferramentas apropriadas à manutenção. Embora a classificação nem sempre seja uma tarefa muito simples, os equipamentos, para efeito da manutenção no $\mathrm{CME}$, são agrupados conforme a especialidade de cada área técnica, seguindo os parâmetros intrínsecos à sua constituição, para que o processo de manutenção seja iniciado.

- Equipamentos Eletrônicos: De maneira generalizada, são classificados como equipamentos eletrônicos aqueles que têm na maioria do seu circuito, componentes eletrônicos, tais como: equipamentos biomédicos e análise clínica, de laboratórios, de som e de imagem. Cita-se como exemplo: Monitores de vídeo para microcomputadores e outros, equipamentos de som e projetores de multimídia, balanças eletrônicas, fax, e outros.

- Equipamentos de Informática: Neste grupo estão quase todos os equipamentos e periféricos destinados à informática, como computadores, microcomputadores, impressoras, scaners e equipamentos de transmissão e recepção de dados.

- Equipamentos Eletromecânicos: Estão agrupados como equipamentos eletromecânicos aqueles constituídos de partes elétricas e partes mecânicas, 
citando-se como exemplo: motobombas, compressores, centrífugas, agitadores, equipamentos de limpeza, e alguns equipamentos odontológicos.

- Equipamentos Eletrotécnicos: Estão agrupados os equipamentos elétricos, eletromagnéticos e de aquecimento. Cita-se como exemplo: motores, transformadores, autoclaves, aquecedores, iluminadores, destiladores e alguns equipamentos odontológicos.

- Equipamentos Ópticos e de Mecânica Fina: Estão classificados neste grupo os equipamentos que são constituídos de partes e peças mecânicas de precisão, assim como os equipamentos ópticos e seus acessórios, destacando-se os microscópios, teodolitos, lunetas, telescópios, projetores de filme, projetores de slides, projetores de transparência.

- Equipamentos Mecânicos: Abrangem todos os equipamentos com partes, sistemas ou elementos móveis. No CME, os equipamentos mecânicos são classificados em dois grupos: equipamentos de refrigeração e equipamentos de mecânica geral.

○ Equipamentos de Refrigeração: Todos os equipamentos de conforto ambiental e outros de refrigeração. Dentre eles citam-se: condicionador de ar, freezer, geladeiras, bebedouros, maquinas de fabricação de gelo, câmaras frias.

○ Equipamentos de Mecânica Geral: Na atividade de manutenção é muito comum a confecção e adaptação de peças, podendo ser fundidas, usinadas, soldadas, cortadas, serradas, etc. Dessa forma, diversos equipamentos podem estar enquadrados neste grupo, dependendo da natureza da intervenção.

\subsubsection{Outros serviços prestados pelo CME}

Além da manutenção, o CME disponibiliza outros serviços à comunidade universitária, como o de especificação técnica, homologação e aceite nos processos de compra de novos equipamentos, e de parecer técnico nos processos de baixa patrimonial.

Esta participação é considerada um aspecto importante, pois diante do princípio de que o processo de manutenção tem início antes da aquisição do equipamento, a especificação técnica visa à adequação do bem adquirido às necessidades do usuário, ao tipo 
de utilização e ao desempenho que dele se espera, mas também procura garantir o cumprimento de exigências relativas ao fornecimento de manuais de operação e de manutenção, de diagramas esquemáticos, desenhos mecânicos e informações detalhadas sobre o funcionamento. A homologação consiste na verificação da adequação da proposta em relação às especificações anteriormente definidas e o aceite, na confirmação de que o bem fornecido está de acordo com a proposta. Ter um equipamento bem dimensionado, operando dentro das condições em que foi concebido é condição fundamental para a garantia de prolongamento da sua vida útil, trazendo ainda outros benefícios que podem facilitar os processos de manutenção.

Embora seja bastante ampla na aquisição dos equipamentos de informática, a atuação do CME é ainda pequena quanto aos demais equipamentos, em especial aqueles de caráter científico e os adquiridos pelas fundações de apoio e por convênios com outras instituições de fomento à pesquisa.

Nas solicitações de baixa patrimonial, a atuação do CME se mostrou mais eficiente a partir de 2004, conforme pode ser verificado na Figura 3.2, onde os bens considerados inservíveis a determinados usuários e portanto passíveis de serem objeto de baixa, passaram a ser redistribuídos a outros usuários mediante avaliação técnica, acomodando necessidades, evitando aquisições desnecessárias e contendo o ritmo de obsolescência registrado em períodos anteriores.

O CME tem ainda autonomia para promover licitações e contratações de serviços e fornecimento de materiais para a manutenção do parque de equipamentos da UnB, mantendo estoque de partes e peças de reposição, além de contratar empresas especializadas para a execução dos serviços considerados economicamente inviáveis para a Universidade. Essa autonomia garante maior agilidade na aquisição de materiais de consumo e na terceirização dos serviços, beneficiando todo o processo de manutenção.

\subsection{METODO UTILIZADO}

\subsubsection{Tipo de pesquisa}

A partir da proposta classificação de Vergara (2000), definiu-se realizar pesquisas exploratória, descritiva e explicativa quanto aos fins e documental e de campo, quanto aos meios, com o objetivo de avaliar o grau de satisfação dos usuários do CME. 
Quanto aos fins, a pesquisa será exploratória, porque inexistem avaliações sobre a satisfação dos usuários do CME, apesar desse serviço ser prestado desde 1987. Descritiva, pois buscará correlacionar as variáveis que compõem a satisfação com os tipos de manutenção de equipamentos praticados pelo Centro. Explicativa, na medida em que buscará identificar os fatores formadores da satisfação, bem como os meios de aumentar o grau de satisfação.

Quanto aos meios, a pesquisa será documental, procurando avaliar, através dos arquivos, a quantidade de ordens de serviço concluídas ao longo de um determinado período de tempo, o quadro de pessoal utilizado e a produtividade.

A pesquisa de campo se dará através da aplicação de questionário, que conterá seis questões fechadas e três abertas. Nas questões fechadas, os respondentes poderão manifestar o seu grau de satisfação, tanto a nível geral, quanto a ordens de serviço específicas e individuais. Com as questões abertas, pretende-se identificar os motivos da satisfação e/ou insatisfação e colher sugestões que, na visão do usuário, possam melhorar o atendimento.

\subsubsection{Amostra ou participantes da pesquisa}

A pesquisa documental abrangeu o período de janeiro de 2003 a julho de 2006, no qual há registro das solicitações de reparo atendidas pelo CME, sendo possível identificar o tipo do equipamento, seu número patrimonial, o solicitante ou usuário e as datas da solicitação e atendimento.

Os equipamentos foram agrupados por tipo de uso - pesquisa, ensino e apoio administrativo. Tiveram tratamento diferenciado os equipamentos que possuem planos de manutenção preventiva e os que são objeto de manutenção corretiva, visando identificar diferenças que permitam correlacionar o grau de satisfação com os tipos de manutenção descritos no referencial teórico.

A pesquisa de campo englobou todos os atendimentos concluídos durante o mês de maio de 2006, independentemente da data em que foram emitidas as ordens de serviço, num total de 994 atendimentos. A distribuição das ordens de serviço atendidas em relação ao tempo em que foram emitidas é mostrada nas Tabelas 3.1a e 3.1b. 


\begin{tabular}{|c||c|c|c|c|c|c|}
\hline \multicolumn{7}{|c|}{ Tabela 3.1a - Ordens de Serviço Atendidas 2000 a 2005 } \\
\hline Ano & 2000 & 2001 & 2002 & 2003 & 2004 & 2005 \\
\hline Quantidade & 2 & 3 & 3 & 5 & 11 & 30 \\
\hline \hline
\end{tabular}

\begin{tabular}{|c||c|c|c|c|c|c|}
\hline \multicolumn{7}{|c|}{ Tabela 3.1b - Ordens de Serviço Atendidas 2006 } \\
\hline Mês & janeiro & fevereiro & março & abril & maio & Total \\
\hline Quantidade & 15 & 26 & 139 & 243 & 516 & 994 \\
\hline
\end{tabular}

As ordens de serviço foram agrupadas em 310 usuários ou Centros de Custo, aos quais foram enviados os questionários.

\subsubsection{Hipóteses}

A formulação das hipóteses levou em consideração o caráter institucional dos serviços prestados pelo Centro, sendo os custos de materiais e mão-de-obra absorvidos de forma integral pela Instituição. Por outro lado, com exceção de equipamentos cuja manutenção, por sua especificidade, não possa ser realizada pelo CME, não existe para o usuário a opção de realizar o serviço em outro local.

Assim, partiu-se da premissa de que os componentes da satisfação seriam:

1. O tempo decorrido entre a solicitação de reparo e o primeiro contato do técnico com o solicitante, definido como "Tempo de Resposta".

2. O tempo decorrido entre a solicitação de reparo e a conclusão do serviço, definido como "Tempo Total de Manutenção".

3. A importância atribuída pelo usuário ao equipamento, definido como "grau de importância".

\subsubsection{Instrumento}

O instrumento foi construído com 9 itens, dos quais 6 buscam avaliar a satisfação dos usuários com o serviço, medida em uma escala de amplitude de 5 pontos, variando de "muito insatisfeito" a "muito satisfeito" com um ponto neutro intermediário. 
No primeiro item do questionário, avaliado nesta escala de satisfação, é solicitado o grau de satisfação quanto a todos os aspectos da manutenção de equipamentos realizada pelo $\mathrm{CME}$.

No segundo, terceiro e quarto itens, solicitam-se, respectivamente, o grau de satisfação, o tempo de resposta, o tempo total e o grau de importância atribuído pelo usuário a um equipamento específico.

O sexto item refere-se ao grau de satisfação quanto às informações recebidas no decorrer da manutenção, onde o entrevistado poderá avaliar o nível da comunicação com o CME.

As duas primeiras questões abertas dizem respeito aos aspectos que influenciaram a resposta dada quanto à satisfação geral, à satisfação especifica e à importância que o equipamento tem para o usuário e a terceira, abre um espaço para o entrevistado sugerir melhorias no atendimento.

Assim, espera-se que os fatores determinantes da satisfação - a qualidade dos serviços prestados e os tempos de resposta e total, vinculados ao grau de importância que o usuário atribui ao equipamento - possam fornecer elementos a uma análise qualitativa. $\mathrm{O}$ usuário pode estar insatisfeito com os serviços, de uma forma geral, e demonstrar satisfação com um item específico, ou ao contrário, ter boa avaliação global e manifestar insatisfação com um item.

Como forma de facilitar a identificação pelo respondente, de cada equipamento, foram informados no questionário o tipo do equipamento, seu número patrimonial e o número da ordem de serviço na qual foi solicitado o reparo.

\subsubsection{Procedimentos}

Os questionários foram enviados aos usuários por correio eletrônico. Devido ao baixo número de respostas obtidas, foram reenviados formulários impressos e realizados contatos telefônicos, explicando os motivos e reforçando a solicitação de resposta. Diante disto, retornaram 31 questionários, opinando sobre a manutenção de 158 equipamentos. 


\section{Análise e Discussão}

Neste capítulo serão apresentados e analisados os dados obtidos nos arquivos eletrônicos do CME e os resultados da pesquisa de campo realizada com os usuários dos serviços de manutenção de equipamentos da UnB.

\subsection{Pesquisa documental}

Foram avaliados, para a obtenção dos dados, os registros eletrônicos relativos ao atendimento de solicitações de manutenção nos anos de 2001 a 2005 . A Figura 4.1 mostra a evolução da quantidade total de solicitações, dos atendimentos realizados e dos equipamentos objeto de baixa patrimonial no período.

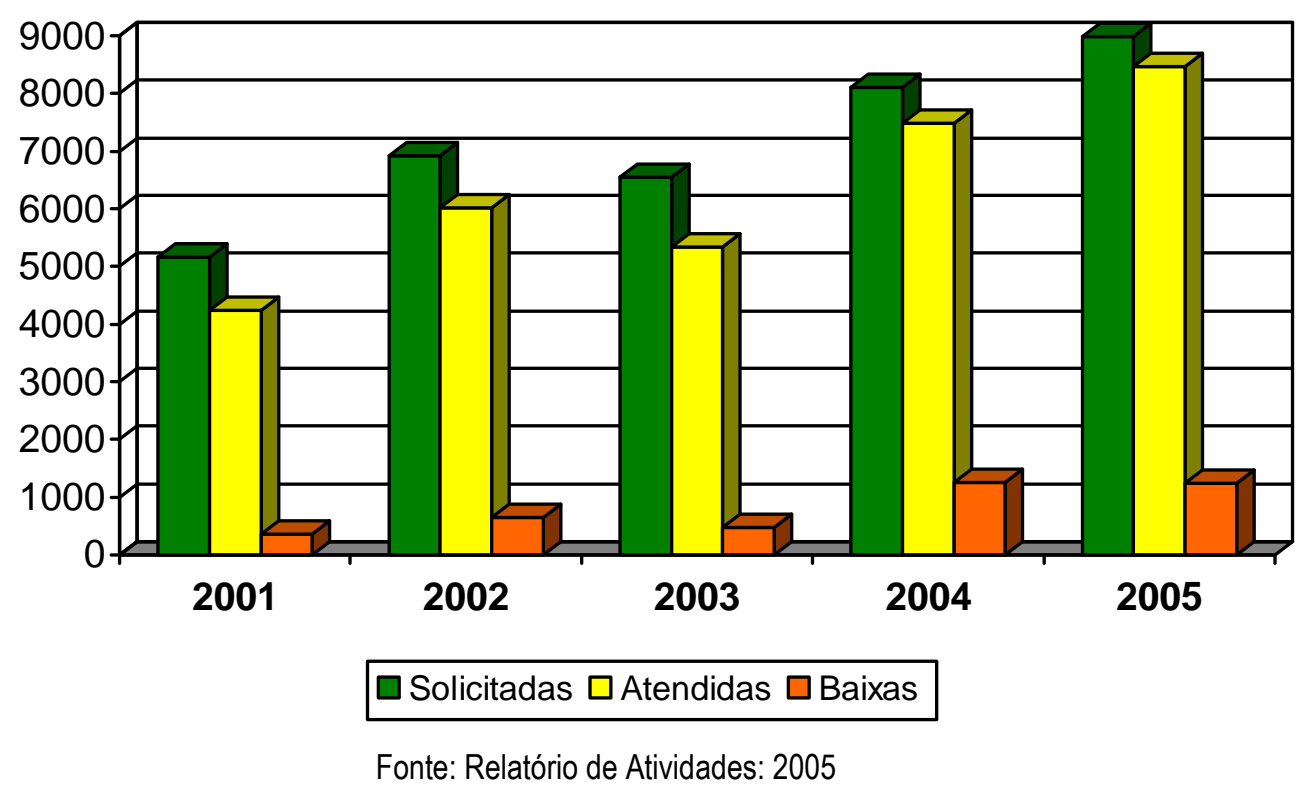

Figura 4.1 - Evolução das Solicitações, Atendimentos e Baixa do Acervo Patrimonial.

Observa-se entre os anos de 2001 a 2005, variação de 74,28\% no total de solicitações recebidas, com um crescimento médio anual de $14,86 \%$, contra uma variação $99,76 \%$ e crescimento médio $19,95 \%$ ao ano, quanto ao atendimento das solicitações. Já as baixas patrimoniais cresceram $242 \%$, com média anual de $46,56 \%$. Verifica-se a tendência de crescimento, com exceção do ano de 2003, no qual, segundo informações não-documentais, porém confirmadas por servidores do CME, a baixa qualidade dos serviços prestados provocou a fuga de diversos usuários. Os dados mostram que os atendimentos concluídos 
tiveram crescimento superior às solicitações, refletindo maior produtividade, uma vez que o quadro de pessoal permaneceu constante no período. Apesar de não haver dados relativos à elevada variação do número de baixas patrimoniais, infere-se que a grande quantidade de equipamentos "descartáveis" ou passíveis de rápida obsolescência explique tal comportamento, como é o caso de impressoras e micro computadores.

Na Tabela 4.1, com dados obtidos dos Anuários Estatísticos da UnB, são mostrados os números relativos à evolução da população universitária no período de 1994 a 2004, por segmento - Alunos de Graduação, de Pós-Graduação, Professores e Técnicos Administrativos - e da quantidade de laboratórios existentes no período de 1999 a 2004.

\begin{tabular}{|c|c|c|c|c|c|c|}
\hline \multicolumn{7}{|c|}{ Tabela 4.1 - Indicadores do Crescimento da Universidade de Brasília } \\
\hline Ano & $\begin{array}{c}\text { Alunos de } \\
\text { Graduação }\end{array}$ & $\begin{array}{c}\text { Alunos de } \\
\text { Pós-graduação }\end{array}$ & Professores & $\begin{array}{c}\text { Técnicos } \\
\text { Administrativos }\end{array}$ & $\begin{array}{c}\text { População } \\
\text { Total }\end{array}$ & Laboratórios \\
\hline 1994 & 12.758 & 1.804 & 1.276 & 2.376 & 18.214 & - \\
\hline 1995 & 13.729 & 2.029 & 1.271 & 2.626 & 19.655 & - \\
\hline 1996 & 14.341 & 2.503 & 1.287 & 2.361 & 20.492 & - \\
\hline 1997 & 15.669 & 2.602 & 1.352 & 2.225 & 21.848 & - \\
\hline 1998 & 16.519 & 3.631 & 1.384 & 2.146 & 23.680 & 292 \\
\hline 1999 & 17.381 & 7.731 & 1.356 & 2.081 & 28.549 & 305 \\
\hline 2000 & 18.208 & 8.507 & 1.343 & 2.034 & 30.092 & 305 \\
\hline 2001 & 20.901 & 8.279 & 1.323 & 2.001 & 32.504 & 324 \\
\hline 2002 & 21.734 & 7.109 & 1.361 & 2.074 & 32.278 & 370 \\
\hline 2003 & 22.310 & 8.244 & 1.298 & 2.278 & 34.130 & 396 \\
\hline 2004 & 21.869 & 8.769 & 1.293 & 2.359 & 34.290 & 437 \\
\hline
\end{tabular}

Fonte: Anuário Estatístico UnB: 2005

Nota-se que enquanto o número de alunos cresceu de forma contínua, especialmente os de pós-graduação, bem como a quantidade de laboratórios, a quantidade de professores e de técnicos administrativos manteve-se praticamente constante, o que mostra um ganho efetivo nos índices de produtividade da Universidade como um todo. No caso do CME esses índices são também bastante representativos, refletindo a implementação de políticas de planejamento e de gestão de pessoal.

A Figura 4.2 mostra a quantidade de ordens de serviço atendidas nos anos de 2003 a 2005 por equipamento, classificados em função da sua destinação - pesquisa, ensino ou administrativa. 


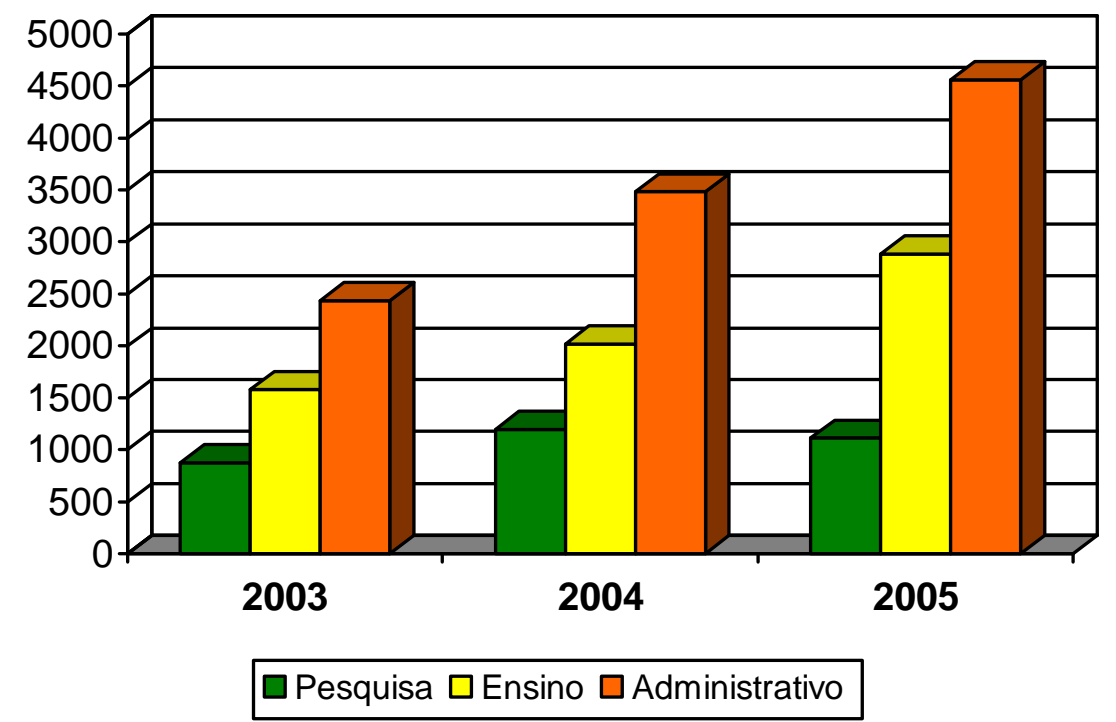

Fonte: Relatório de Atividades CME: 2005

Figura 4.2 - Atendimentos por tipo de utilização.

As taxas de crescimento dos atendimentos a estes equipamentos - pesquisa, ensino e de uso administrativo - foram de $27,86 \%, 81,81 \%$ e $86,87 \%$, respectivamente.

A Tabela 4.2 mostra a quantidade de atendimentos por tipo de equipamento, independentemente de sua utilização, seguindo a classificação do registro patrimonial. Nesta tabela vê-se que os cinco primeiros equipamentos representam 52,37\% das intervenções de manutenção realizadas. Os aparelhos agrupados na tabela como outros equipamentos, totalizam 8.265 unidades, representando $24,12 \%$ das intervenções em 766 tipos diferentes. 


\begin{tabular}{|c|l|r|r|}
\hline \multicolumn{3}{|c|}{ Tabela 4.2 - Intervenções de Manutenção janeiro de 2003 a junho de 2006} \\
\hline Ord & \multicolumn{1}{|c|}{ QTD } & \multicolumn{1}{c|}{$\%$} \\
\hline $1^{\circ}$ & Microcomputador/Acessório/Componente & 9.519 & $27,78 \%$ \\
\hline $2^{\circ}$ & Monitor de Vídeo & 2.496 & $7,29 \%$ \\
\hline $3^{\circ}$ & Microscópio Binocular & 2.013 & $5,88 \%$ \\
\hline $4^{\circ}$ & Impressora Jato de Tinta & 1.988 & $5,80 \%$ \\
\hline $5^{\circ}$ & Aparelho de Ar Condicionado & 1.928 & $5,63 \%$ \\
\hline $6^{\circ}$ & Copiadora/Impressora & 952 & $2,78 \%$ \\
\hline $7^{\circ}$ & Impressora Laser & 897 & $2,62 \%$ \\
\hline $8^{\circ}$ & Bebedouro Refrigerado Tipo Pressão & 726 & $2,12 \%$ \\
\hline $9^{\circ}$ & Estabilizador Eletronico & 693 & $2,02 \%$ \\
\hline $10^{\circ}$ & Microscópio Estereoscópico & 693 & $2,02 \%$ \\
\hline $11^{\circ}$ & Teclado P/Equipamento de Proc.de Dados & 593 & $1,73 \%$ \\
\hline $12^{\circ}$ & Retroprojetor & 569 & $1,66 \%$ \\
\hline $13^{\circ}$ & Projetor de Imagem Microcomputador/Multimídia & 502 & $1,47 \%$ \\
\hline $14^{\circ}$ & Microscópio & 399 & $1,16 \%$ \\
\hline $15^{\circ}$ & Microscópio Monocular & 390 & $1,14 \%$ \\
\hline $16^{\circ}$ & No Break & 342 & $1,00 \%$ \\
\hline $17^{\circ}$ & Fac-Símile-Fax & 287 & $0,84 \%$ \\
\hline $18^{\circ}$ & Estereomicroscópio Binocular & 282 & $0,82 \%$ \\
\hline $19^{\circ}$ & Microscópio Estereoscópico Binocular & 258 & $0,75 \%$ \\
\hline $20^{\circ}$ & Ventilador de Parede & 240 & $0,70 \%$ \\
\hline $21^{0}$ & Televisor/Tv & 229 & $0,67 \%$ \\
\hline & Outros Equipamentos (766 tipos distintos) & 8.265 & $24,12 \%$ \\
\hline & & 34.261 & $100 \%$ \\
\hline
\end{tabular}

As Figuras 4.3, 4.4 e 4.5 apresentam a evolução do número de intervenções concluídas nos equipamentos com número de ordem $1^{\circ}, 2^{\circ}, 4^{\circ}$ e $5^{\circ}$ na tabela anterior, de janeiro de 2003 a junho de 2006 e cujo plano de manutenção é corretiva.

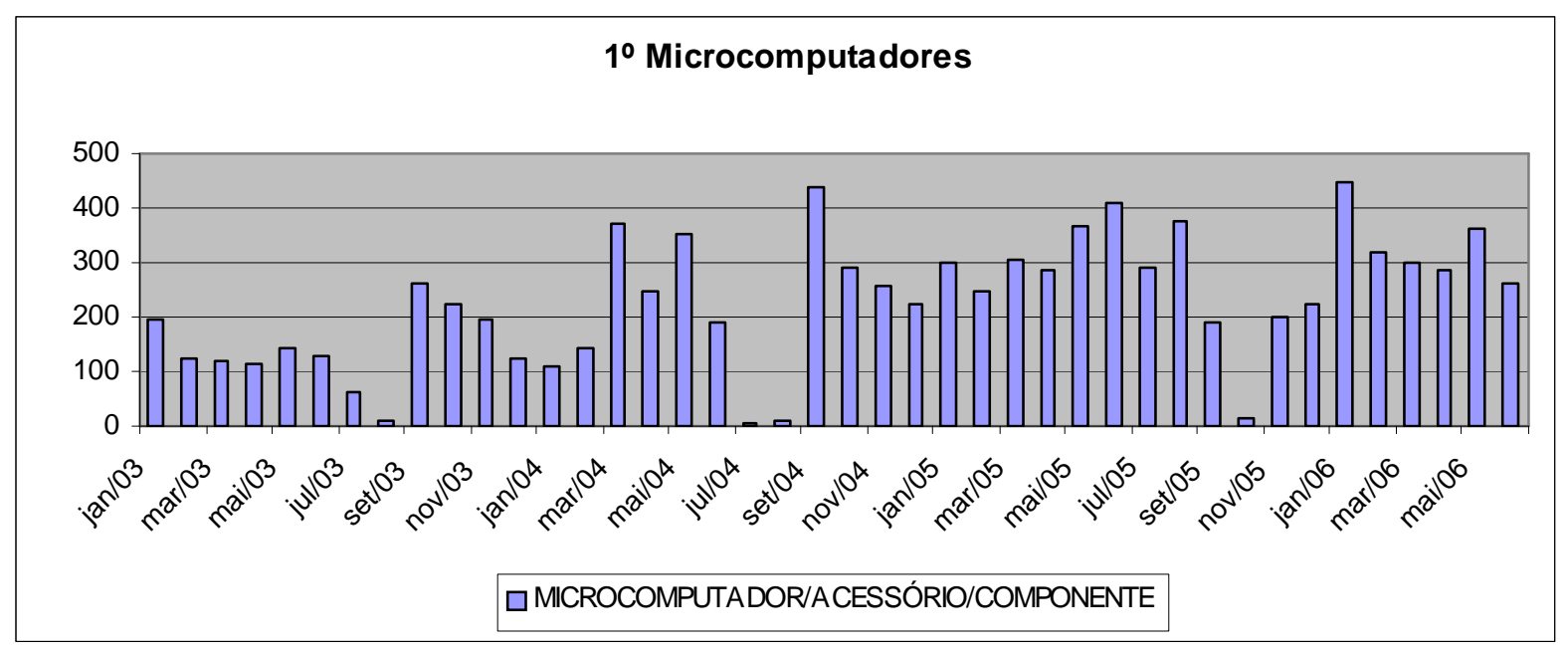

Figura 4.3 - Quantidade de microcomputadores atendidos. 


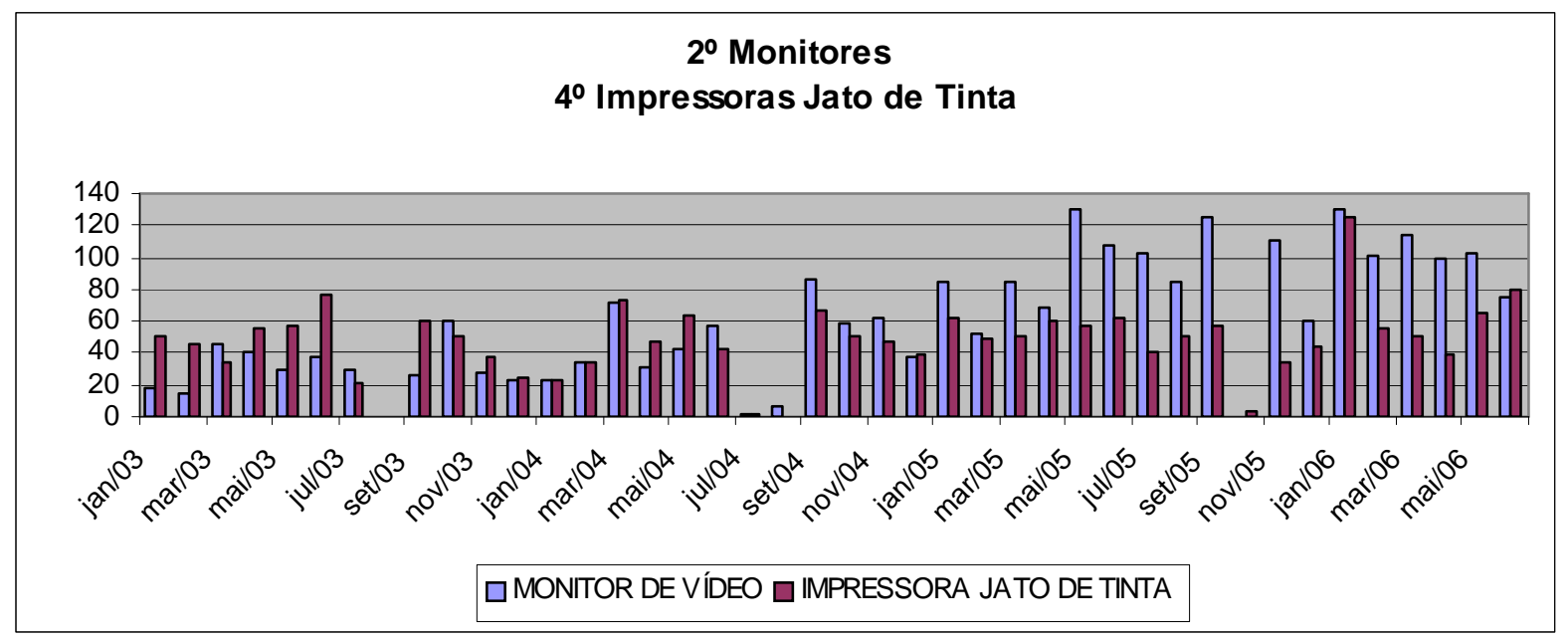

Figura 4.4 - Quantidade de monitores de vídeo e impressoras jato de tinta atendidos.

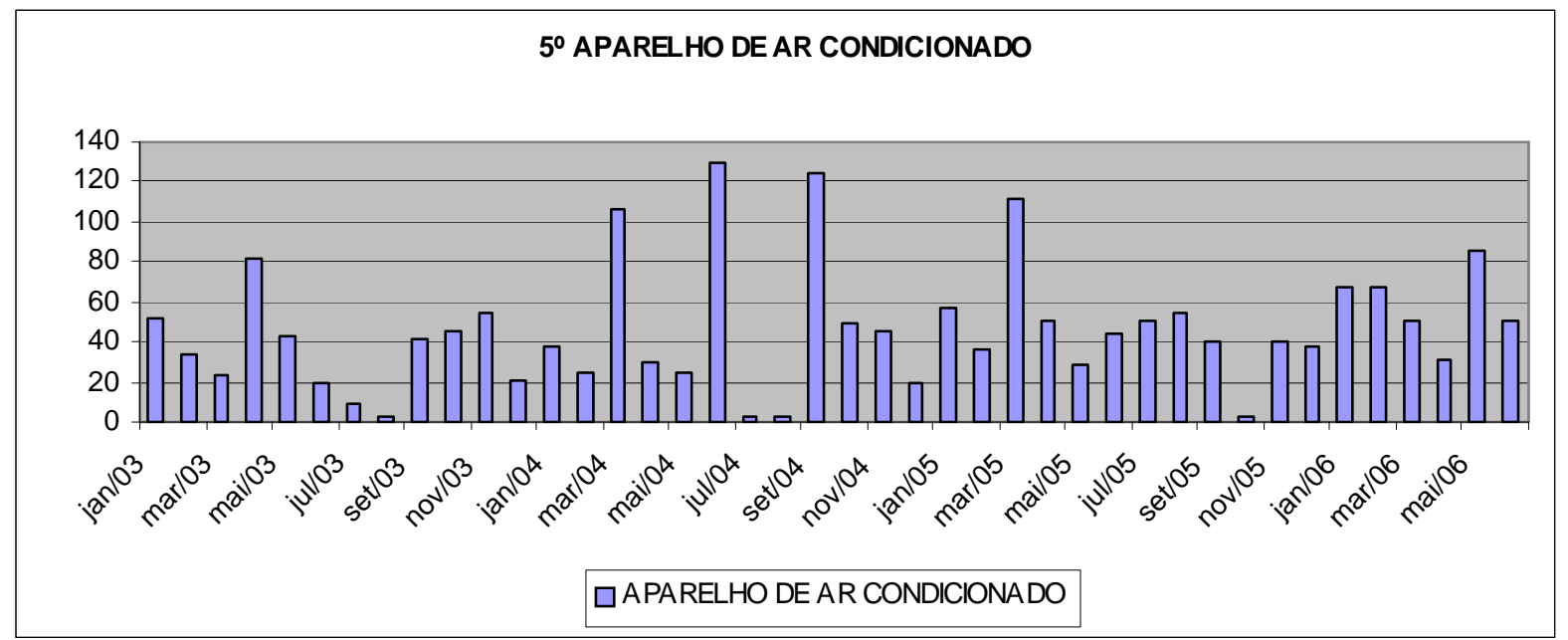

Figura 4.5 - Quantidade de aparelhos de ar condicionado atendidos.

A queda na produção nos meses de agosto de 2003, julho e agosto de 2004 e outubro de 2005 se deu em virtude dos períodos de greve na UnB, nos quais foram paralisados diversos setores da Instituição e também o serviço de manutenção.

Os atendimentos aos equipamentos que têm planos de manutenção preventiva, com números de ordem $3^{\circ}$ e $10^{\circ}$ na Tabela 4.2, são mostrados nas Figuras 4.6 e 4.7 . 


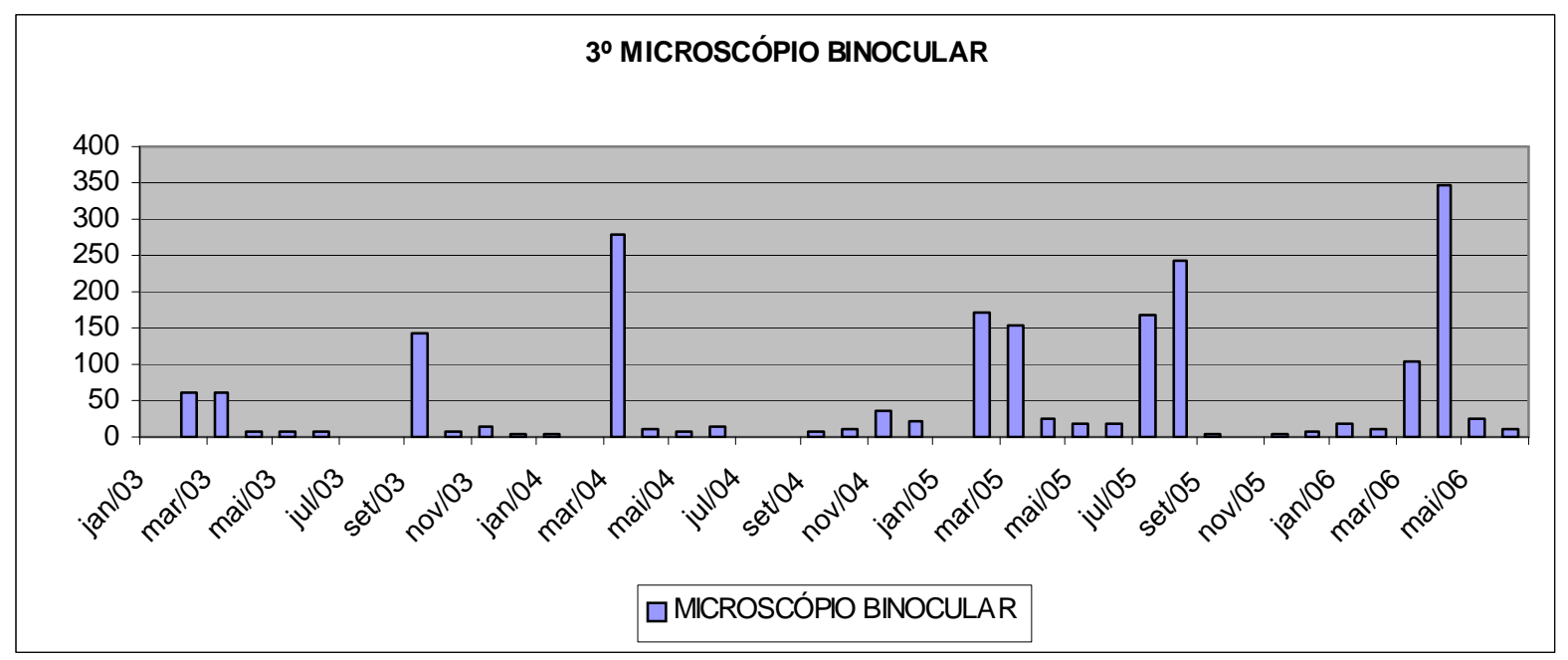

Figura 4.6 - Quantidade de microscópios binocular atendidos.

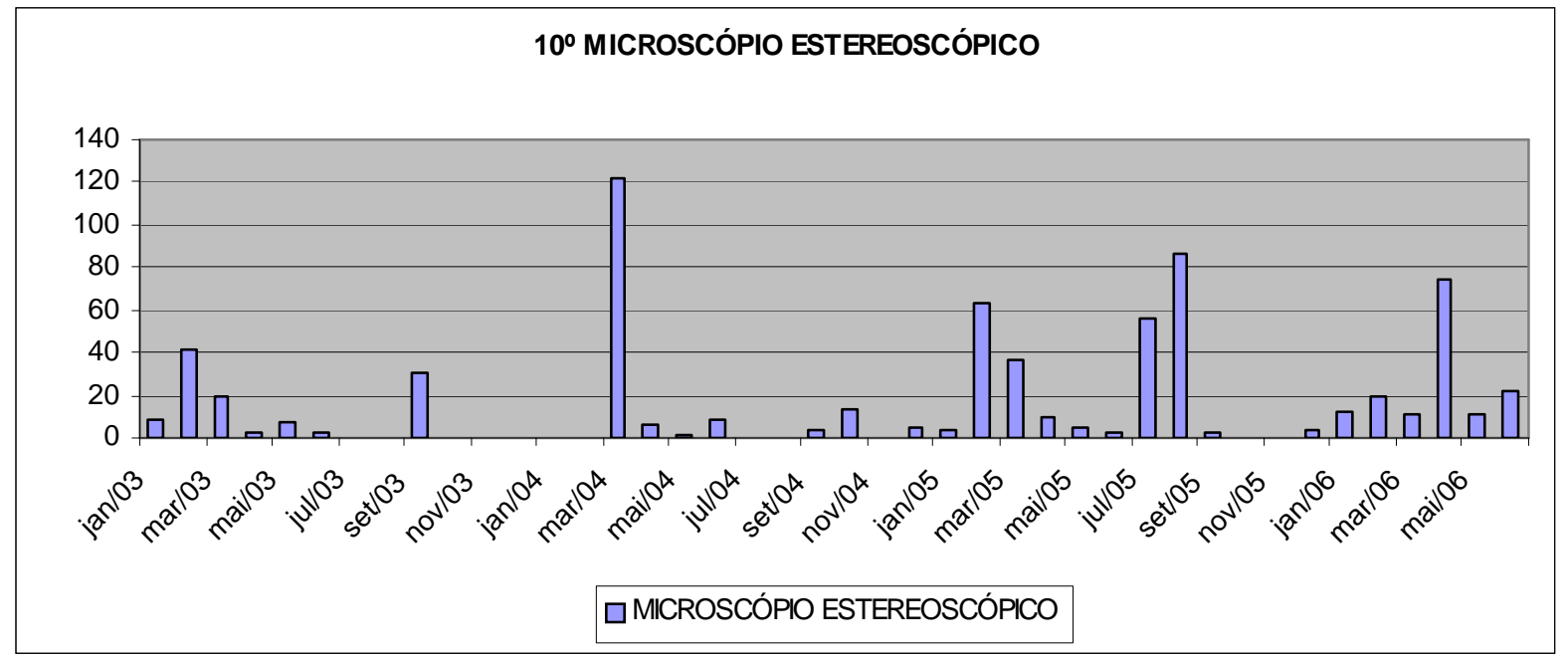

Figura 4.7 - Quantidade de microscópio estereoscópico atendidos.

A distribuição dos atendimentos nestas figuras mostra que em certos meses há um número elevado de intervenções e em outros o número é pouco expressivo. Os meses de maior expressão nos gráficos, representam a execução do plano de manutenção preventiva. Em contrapartida, observa-se que após a intervenção planejada, o número de atendimento por quebra do equipamento tende a valores muito baixos.

A comparação da seqüência de figuras permite verificar a vantagem da manutenção preventiva sobre a corretiva, além de demonstrar que a falta de planejamento favorece a ocorrência de paradas aleatórias, que sobrecarregam as equipes de manutenção em momentos nos quais as mesmas podem não estar preparadas para atender a tais demandas. 
Observa-se também, na comparação das figuras, que nem mesmo o fator greve deu origem ao surgimento de sobrecargas de trabalho, que ocorrem naturalmente, quando as greves terminam.

A Tabela 4.3, relativa aos equipamentos que tiveram os maiores números de solicitações de serviço entre julho de 2005 e junho de 2006 e obtida com dados do Sistema de Controle da Manutenção, mostra a média aritmética dos tempos gastos com a manutenção destes equipamentos.

\begin{tabular}{|l|c|c|}
\hline \multicolumn{3}{|c|}{$\begin{array}{c}\text { Tabela 4.3 - Tempos Médios Gastos na Manutenção mais Representativos } \\
\text { (julho de 2005 a junho de 2006) }\end{array}$} \\
\hline & $\begin{array}{c}\text { Tempo de Resposta } \\
\text { (hhh:mm) }\end{array}$ & $\begin{array}{c}\text { Tempo Total de } \\
\text { Manutenção }\end{array}$ \\
\hline Correção de Defeitos em Microcomputadores & $106: 07 \mathrm{hs}$ & $443: 10 \mathrm{hs}$ \\
\hline Correção de Defeitos em Monitores de Vídeo & $152: 06 \mathrm{hs}$ & $737: 54 \mathrm{hs}$ \\
\hline Correção de Defeitos em Microscópios Binoculares & $98: 19 \mathrm{hs}$ & $292: 56 \mathrm{hs}$ \\
\hline Correção de Defeitos em Impressoras Jato de Tinta & $134: 03 \mathrm{hs}$ & $728: 56 \mathrm{hs}$ \\
\hline Manutenção preventiva em Microscópios & - & $7: 21 \mathrm{hs}$ \\
\hline
\end{tabular}

Neste grupo de equipamentos destacam-se os microscópios, que têm plano de manutenção preventiva. Nesse caso, por ser a intervenção planejada, deixa de existir o tempo de resposta, visto que a solicitação não parte do usuário e a execução acontece com o equipamento em condições de uso, o que explica o menor tempo total de manutenção. Outro fator que contribui para a redução do tempo de indisponibilidade do equipamento é a natureza intrínseca do planejamento, pois numa ação planejada estão previstos a organização das ferramentas necessárias, os procedimentos e o material de consumo a ser empregado, não havendo por que iniciar intervenção em equipamento que está em funcionamento e deixá-lo parado, aguardando outro procedimento ou a compra de peça de reposição. Pode-se observar ainda, que no caso de ocorrência de falhas neste tipo de equipamento, quando então a manutenção é solicitada pelo usuário, os tempos de resposta e total são substancialmente menores, se comparados aos demais equipamentos que não têm plano de manutenção preventiva.

\subsection{Pesquisa de Campo}

Os questionários para aferição do grau de satisfação dos usuários com os serviços prestados pelo CME foram enviados a 310 agentes que tiveram solicitações de manutenção atendidas no mês de maio de 2006, num total de 994 questionários, cada um 
representando um equipamento específico. Foram obtidas respostas de 31 usuários (10\%), com um total de 158 questionários respondidos $(15,9 \%)$.

A Figura 4.8 mostra que $81 \%$ dos entrevistados estão satisfeitos ou muito satisfeitos com os serviços prestados pelo CME e a Figura 4.9 retrata a satisfação específica para cada ordem de serviço atendida. Nessa figura, os índices apresentados dizem respeito à qualidade do serviço, ao tempo de resposta e ao tempo total utilizado pela equipe de manutenção na execução do serviço.

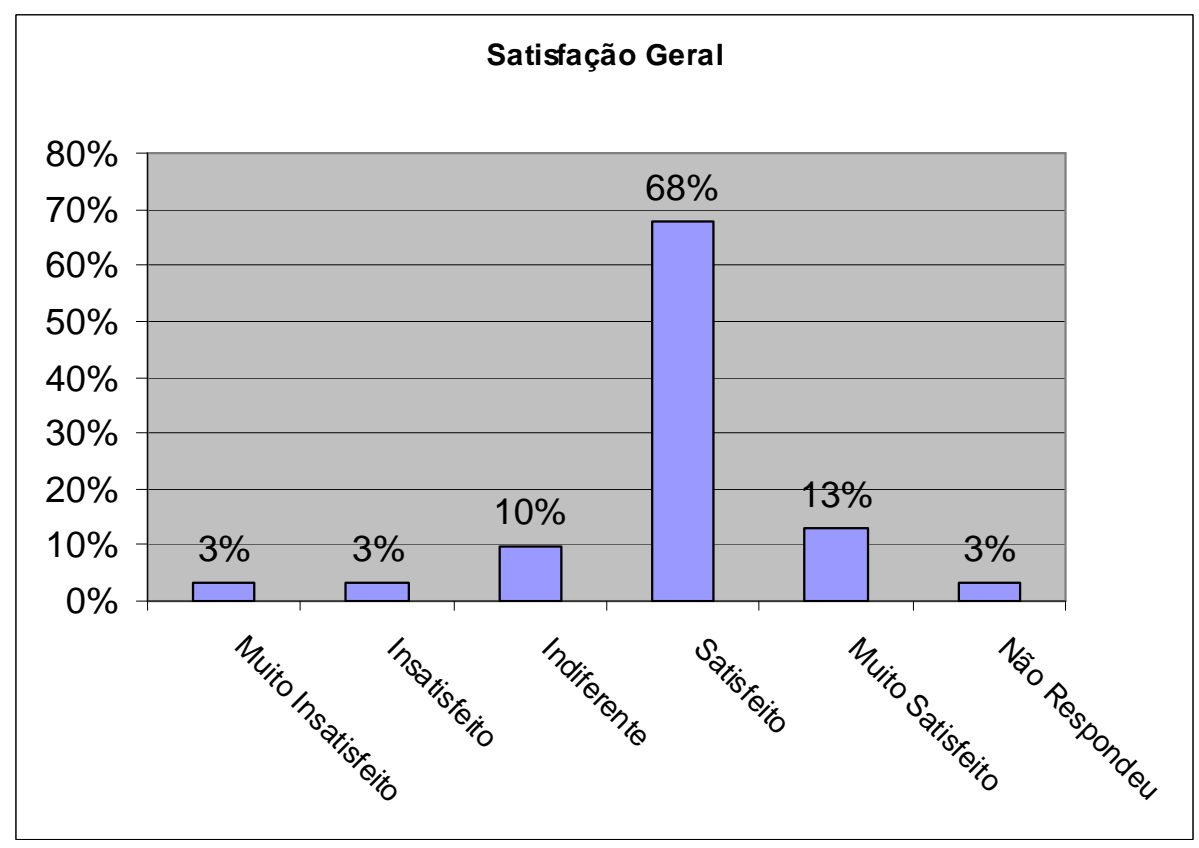

Figura 4.8 - Índice de Satisfação Geral. 


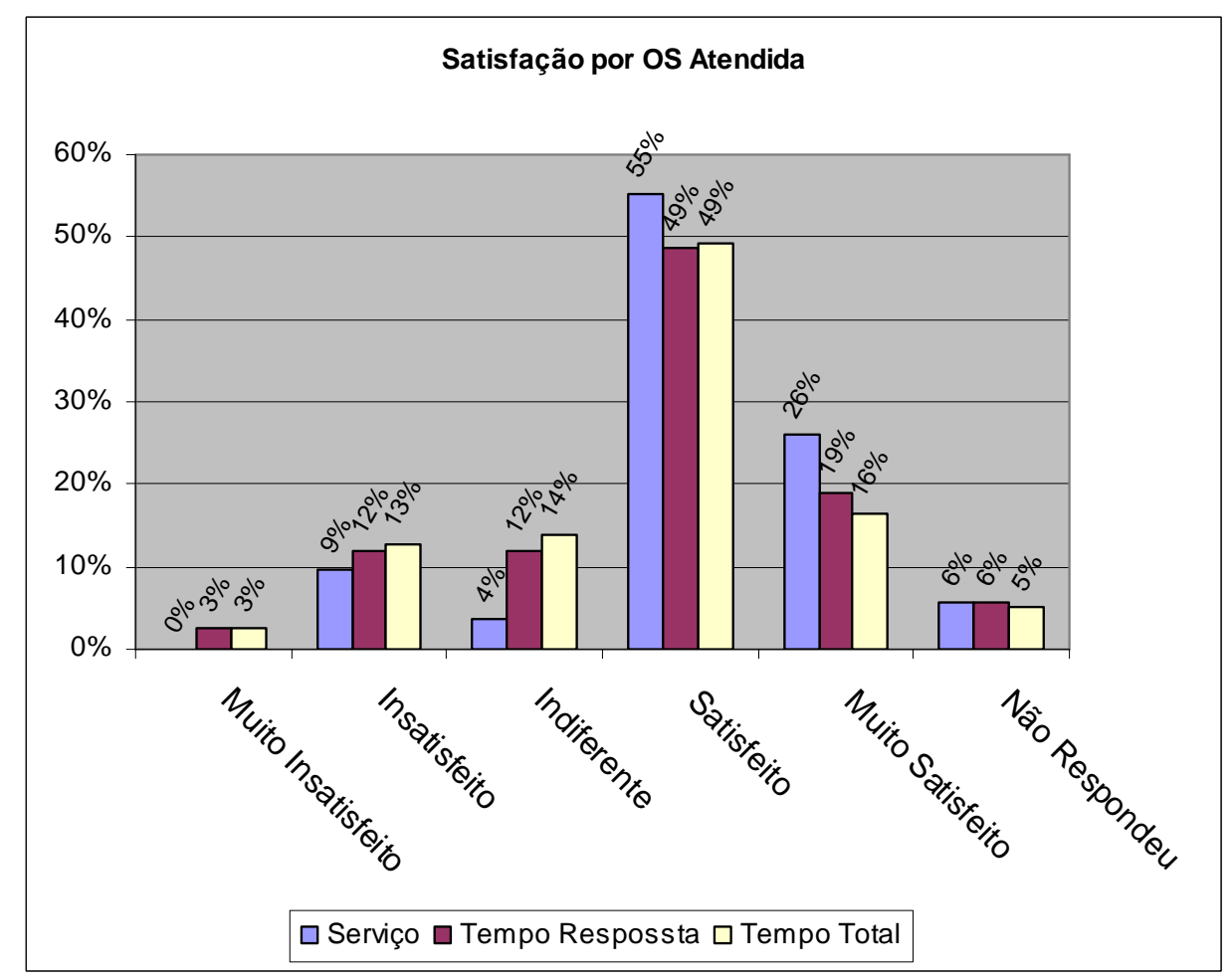

4.9 - Índice de Satisfação por Serviço Executado.

Outro parâmetro avaliado, diz respeito à satisfação que o entrevistado tem com as informações recebidas durante os procedimentos de manutenção. Neste caso, a Figura 4.10 revela que o grau de satisfação com a comunicação é de $74 \%$ entre aqueles entrevistados satisfeito e muito satisfeitos.

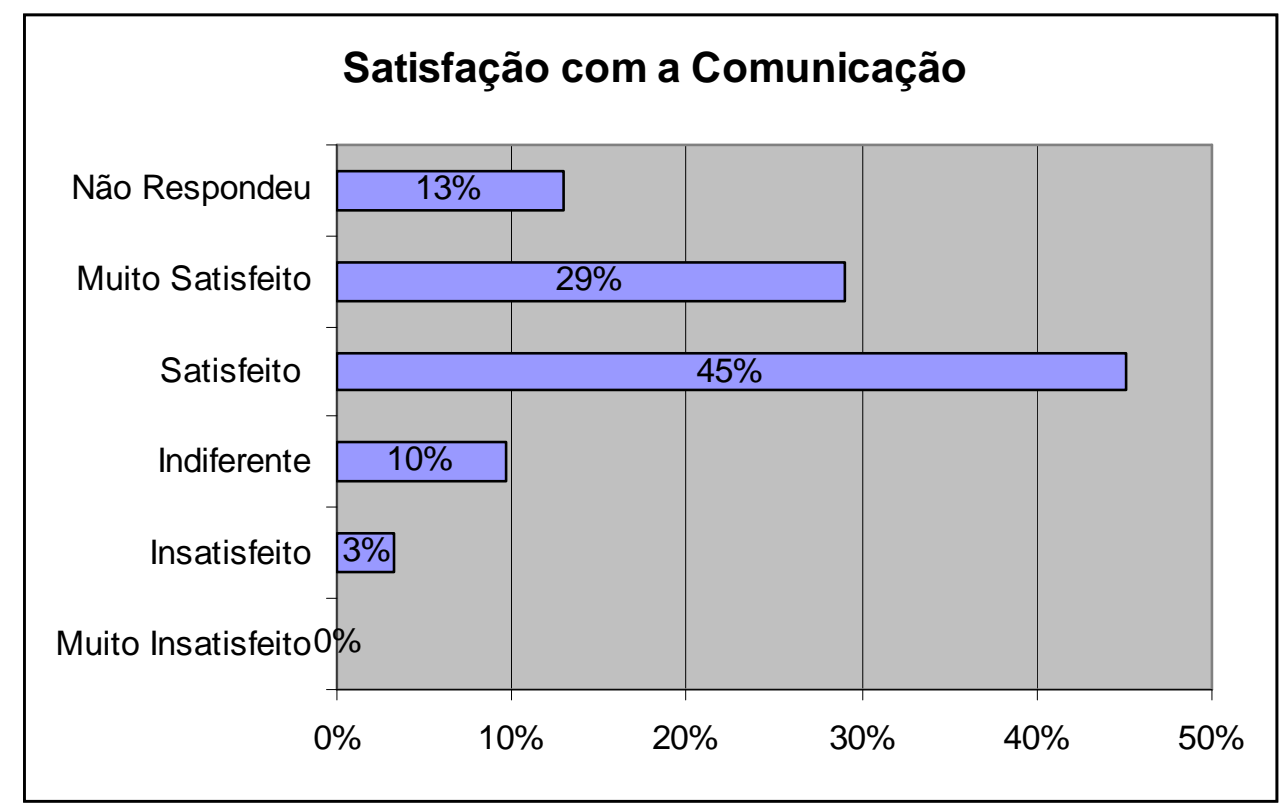

4.10 - Índice de satisfação com a comunicação. 
Os motivos ressaltados pelos usuários muito insatisfeitos e insatisfeitos foram "o atendimento precário" e "o atendimento muito demorado". Estes usuários apresentam como sugestões "a contratação de mão-de-obra mais qualificada", "maior estoque de peças de reposição" e "maior rapidez no atendimento".

Os usuários indiferentes, satisfeitos e muito satisfeitos apresentam como motivos da satisfação, "o prazo entre a solicitação em rede e a coleta dos equipamentos e o prazo entre a coleta e a devolução", "o tempo gasto para manutenção e atendimento com êxito da maioria dos itens solicitados", "a conclusão dos serviços", "a qualidade e o tratamento dos técnicos", "a comunicação com a equipe do CME", o "empenho dos técnicos" e o "o profissionalismo dos técnicos". Nota-se a repetição de motivos ligados ao tempo de atendimento e à conclusão dos serviços em si.

Os usuários muito insatisfeitos e insatisfeitos apresentaram como sugestões, a "contratação de mão-de-obra mais qualificada", "maior rapidez no atendimento" e "mais técnicos para atender de forma descentralizada". Já os usuários indiferentes, satisfeitos e muito satisfeitos têm como sugestões "cursos de capacitação para os técnicos", "melhorar a comunicação", "maior quantidade de técnicos para maior especialização e menor quantidade de equipamentos enviados para manutenção externa", "treinamento dos técnicos e testar o equipamento com o usuário", "contratação de mais técnicos", "treinamento em canetas odontológicas", "maior estoque de peças de reposição" e "sede própria para atender melhor.

A tabulação destas sugestões revela, em ordem decrescente quanto ao número de citações, que as preocupações dos usuários estão voltadas principalmente, para os seguintes aspectos:

- Menor tempo de atendimento;

- Investimento em treinamento e qualificação;

- Melhor comunicação;

- Estoque de peças; e

- Espaço físico.

A confrontação dos resultados da pesquisa documental com a pesquisa de campo confirma a hipótese de que a satisfação dos usuários está ligada de forma estreita com o tempo de atendimento de suas solicitações e a qualidade dos serviços prestados. Mostra ainda que existe uma visão crítica quanto à necessidade de mais treinamento, melhor qualificação dos técnicos e maior abrangência dos serviços prestados. 
Outra confirmação que se obtém das pesquisas é quanto às vantagens e benefícios obtidos com programas de manutenção preventiva. A inexistência do tempo de resposta neste tipo de intervenção contribui para a redução do tempo total, além de oferecer condições de planejamento. A intervenção preventiva pode ser planejada para períodos de menor utilização dos equipamentos, numa distribuição que não afete o processo produtivo da Instituição.

A importância atribuída pelo usuário ao equipamento objeto de solicitação de reparo é retratada na Figura 4.11.

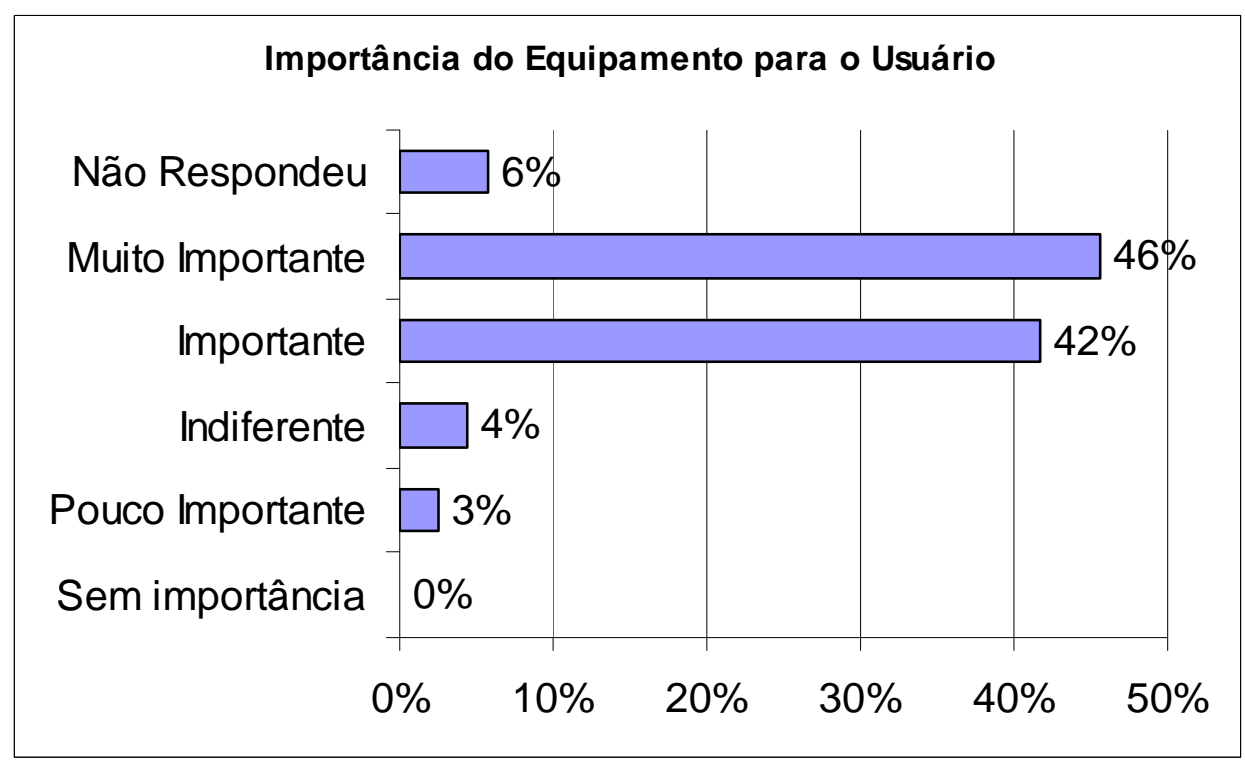

Figura 4.11 - Importância que o usuário confere ao equipamento.

Nota-se que $88 \%$ dos usuários consideram o equipamento sob sua responsabilidade "importante e muito importante", o que dá a noção do transtorno causado pelas paradas imprevistas dos equipamentos. Este fator reforça ainda mais a importância da adoção de modelos de manutenção preventiva mais abrangentes, que incentivem a interação entre os usuários e o CME e permitam o ajuste do cronograma de execução da forma mais conveniente às partes. 


\section{Conclusões}

\subsection{Conclusões Gerais}

A avaliação dos serviços de manutenção de equipamentos da UnB mostra o enorme desafio que é a sua gestão: um grande parque de máquinas a ser mantido, inúmeras variedades e especificidades de equipamentos e diferentes tipos de utilização; por outro lado, vê-se um quadro reduzido de funcionários, com diferentes tipos de vínculo empregatício, salários baixos e não isonômicos, espaço físico inadequado e ainda todos os entraves burocráticos e legais inerentes ao serviço público.

A manutenção é tratada com freqüência como uma função secundária e de pouca importância nas organizações, sendo entendida muitas vezes como um mal necessário ou uma atividade que só gera despesas, sendo esta uma barreira ao seu bom desempenho. $\mathrm{Na}$ realidade, a manutenção deve ter como objetivo ou missão, não apenas o reparo de equipamentos após a ocorrência da quebra, mas sobretudo a prevenção, no sentido de evitar que as quebras ocorram. Numa visão ainda mais ampla, a manutenção pode, além de manter as condições de funcionamento das máquinas, equipamentos e sistemas, buscar a introdução de melhorias que possam colaborar com a obtenção de maior desempenho, menores custos e melhores índices gerais de produtividade. Para que a manutenção atinja esses objetivos, é necessário que sejam implementadas novas políticas de gestão, com o planejamento global de todas as atividades necessárias à sua obtenção. Essas atividades devem incluir revisões gerais periódicas, substituições programadas de peças e equipamentos, fornecimento de peças de reserva, trabalhos de oficina, planos de reparo, implantação de registros históricos, alterações nos equipamentos, etc., resumidas em três características básicas:

- Implantação de programa de manutenção;

- Meios de assegurar o cumprimento do programa; e

- Método de avaliação de registro e avaliação dos resultados.

Segundo Lucatelli (2002), a pequena expressão de conceitos mais avançados na manutenibilidade dos equipamentos é resultado da falta de uma definição política de manutenção. Esta é uma característica da manutenção de equipamentos da Universidade de Brasília, que está organizada com planejamento orientado predominantemente às ações 
corretivas, seguindo os critérios estabelecidos pela NBR 5462 (1994) e englobando basicamente os reparos.

A confrontação dos diferentes tipos e técnicas de manutenção apresentados no Capítulo 2 deste trabalho, com a manutenção que é praticada na UnB, mostrou que a grande maioria dos equipamentos é objeto de manutenção corretiva. Apenas o grupo de equipamentos ópticos, que representaram $11,77 \%$ do total de atendimentos realizados entre janeiro de 2003 e junho de 2006, tem programa de manutenção preventiva implantado. Comparando-se a evolução das intervenções nesses equipamentos com os equipamentos sem manutenção preventiva e principalmente com os tempos médios gastos na manutenção, podese constatar as vantagens da manutenção preventiva, quanto à redução das intervenções imprevistas e o tempo total gasto no processo.

$\mathrm{O}$ alto percentual de usuários satisfeitos com os serviços prestados pelo CME pode ser avaliado como sendo o reflexo de mudanças recentes, especialmente no aspecto de gestão dos recursos humanos, que fizeram aumentar substancialmente a quantidade e a qualidade dos atendimentos. É necessário, entretanto, que novas avaliações confirmem estes dados, sendo previsível que o grau de exigência quanto à qualidade dos serviços cresça na medida em que o atendimento se torne mais eficiente.

Um importante aspecto constatado no serviço de manutenção da UnB é a existência de sistema de registro das ocorrências, vinculado ao Sistema Patrimonial (SIPAT), que permite o acompanhamento pelo usuário das solicitações de reparo, desde a emissão até a conclusão do serviço. Todas as solicitações são executadas com um sistema de gerenciamento que é desencadeado com a emissão da solicitação e que possibilita o acompanhamento do processo da manutenção até a sua conclusão, com a entrega do serviço.

Apesar de possuir estas ferramentas de acompanhamento, registro e controle estatístico das intervenções, o sistema apresenta limitações como a inexistência de controle dos custos da manutenção, o que dificulta a tomada de decisões.

A falta de um sistema de avaliação de custos pode ser um fator de limitação ao desenvolvimento de programas mais abrangentes de manutenção preventiva. Conforme Kardec e Nascif (2006) os diferentes tipos de manutenção podem ser considerados políticas de manutenção, "desde que sua aplicação seja resultado de uma definição gerencial ou política global da instalação, baseada em dados técnico-econômicos”. Pode-se verificar, nas definições dadas aos diferentes tipos de manutenção preventiva, que a medida da eficiência de um programa de manutenção jamais estará completa, caso não se conheça o seu custo. 
A manutenção preventiva apresenta inúmeras vantagens em relação à corretiva. A conveniência de sua adoção, segundo Kardec e Nascif (2006), está ligada à simplicidade da reposição, ao alto custo das falhas e à implicação das falhas na segurança pessoal e operacional, possibilitando o conhecimento prévio das ações, boa condição de gerenciamento e a previsão de consumo de materiais. No entanto, segundo os autores, a manutenção preventiva mal planejada implica a retirada do equipamento ou sistema de operação para a realização dos serviços programados, gerando questionamentos à sua adoção em sistemas onde não haja fatores suficientemente fortes para justificar a sua implementação. Outro fator negativo com relação à manutenção preventiva seria a possibilidade de introdução de defeitos não existentes, em razão de falha humana, defeitos em peças sobressalentes, contaminações em sistemas de lubrificação e danos durante as partidas e paradas (KARDEC e NASCIF, 2006, p. 41).

A regulamentação dos processos de aquisição de equipamentos, de forma a tornar mais abrangente a atuação do CME nas fases de especificação técnica, homologação de propostas e aceite será de grande importância quanto ao aspecto da confiabilidade dos produtos adquiridos, a partir do princípio de que o processo de manutenção se inicia na correta especificação do bem. É bastante comum o erro de considerar que os aspectos mais importantes são os custos de investimento na aquisição dos equipamentos e suas instalações, negligenciando aqueles da manutenção, o que dificulta os procedimentos em caso de defeito. Também é esquecida com frequiência, a verificação da existência de meios locais humanos e materiais para a manutenção dos equipamentos. São inúmeros os casos de equipamentos instalados em condições precárias, em locais inacessíveis, que não permitem manutenção adequada. 


\subsection{Sugestões}

Considerando todos os aspectos abordados neste trabalho, são apresentados a título de sugestão para o desenvolvimento do serviço de manutenção de equipamentos da UnB, os pontos abaixo relacionados, destacando que a implementação de programas de manutenção preventiva, cujas vantagens foram demonstradas neste trabalho, não poderá estar dissociada de outros aspectos importantes à organização e gestão do sistema, de forma eficiente e compatível com as necessidades da Instituição:

- Maior abrangência da manutenção preventiva;

- Adequação do quadro de pessoal;

- Capacitação e treinamento;

- Modernização do sistema de controle da manutenção;

- Sistema de apuração de custos;

- Maior participação nos processos de aquisição de equipamentos; e

- Adequação do espaço físico. 


\section{REFERÊNCIAS}

ASSOCIAÇÃO BRASILEIRA DE NORMAS TÉCNICAS. NBR 5462: confiabilidade e mantenabilidade. Rio de Janeiro, 1994.

FERREIRA, A. B. H. Novo Aurélio Século XXI: o dicionário da língua portuguesa. 3.ed.rev.e ampl. Rio de Janeiro: Nova Fronteira, 1999.

KARDEC, A.; NASCIF, N. Manutenção Função Estratégica.2.ed.3.reimp. Rio de Janeiro: Qualitymark, 2006.

LAFRAIA, J. R. B. Manual de Confiabilidade, Mantenabilidade e Disponibilidade. Rio de Janeiro: Qualitymark, 2002.

LUCATELli, M. V. Proposta de Aplicação da Manutenção Centrada em Confiabilidade em Equipamentos Médico-Hospitalares. 2002. 272 f. Tese (Doutorado em Engenharia Elétrica) - Universidade Federal de Santa Catarina, Florianópolis, 2002.

MAIA Jr., O. B. Procedimentos de Manutenção Baseados na Técnica de ConfiabilidadeRCM: Um caso prático em equipamentos de subestações. 2003. 119 f. Dissertação (Mestrado em Engenharia Elétrica) - Departamento de Engenharia Elétrica. Universidade de Brasília, Brasília, 2003.

MIRANDA, R. L. Qualidade Total. São Paulo: Makron Books, 1994.

MOTTER, O. Manutenção Industrial. O Poder Oculto na Empresa. São Paulo: Hemus Editora, 1992.

RAMIREZ, E. F. F.; CALDAS, E. C.; SANTOS Jr. P. R. Manual Hospitalar de Manutenção Preventiva. Londrina: Editora UEL, 2002.

SILVA, W. C. Manutenção Predial no Banco Central do Brasil. Monografia. Brasília: Faculdade de Estudos Sociais Aplicados. Universidade de Brasília, 1994.

SIQUEIRA, I. P. Manutenção Centrada na Confiabilidade. Manual de Implementação. Rio de Janeiro: Qualitymark, 2005.

UNIVERSIDADE DE BRASILIA. Centro de Manutenção de Equipamentos Científicos. Relatório de Atividades: 2005. Brasília: Universidade de Brasília, 2006.

UNIVERSIDADE DE BRASILIA. Secretaria de Planejamento. Anuário Estatístico UnB: 2005. Brasília: Universidade de Brasília, 2005.

VERGARA, S. C. Começando a definir a metodologia. In : Projetos e relatórios de pesquisa em Administração. 3. ed. São Paulo: Atlas, 2000. cap. 4, p. 46-53. 


\section{Apêndice}

Modelo Utilizado na Pesquisa de Campo

\section{CME::: PESQUISA DE SATISFAÇÃO DO USUÁRIO :::}

O Centro de Manutenção de Equipamentos Científicos, preocupado com o grau de satisfação dos usuários dos serviços de manutenção prestados à Universidade de Brasília e com o objetivo de aperfeiçoar o seu sistema de gestão da qualidade, gostaria de contar com sua colaboração, respondendo a este questionário para nos ajudar a aprimorar continuamente a qualidade dos nossos serviços avaliando o seu grau de satisfação e saber o que você avalia como importante, para que possamos identificar suas necessidades e, assim, melhor atendê-lo.

Agradecemos antecipadamente pelo tempo despedido para o preenchimento do mesmo. Lembramos que as informações disponibilizadas serão de grande proveito para o desenvolvimento das atividades desempenhadas pelo CME na busca uma melhor eficácia como Centro de Custo da UnB e solicitamos que após o preenchimento deste questionário, o mesmo seja enviado para o e-mail cme@unb.br até o dia 16/06/2006.

Indique, marcando com um "X" ao lado dos campos, a sua avaliação utilizando uma escala de 05 (cinco) opções, conforme a descrição abaixo:

1. De modo geral, como você classificaria a sua satisfação em todos os aspectos da manutenção de equipamentos realizada pelo CME:

\begin{tabular}{|l|l|l|l|l|l|l|l|l|l|}
\hline & 1. Muito Insatisfeito & & 2. Insatisfeito & & 3. Indiferente & & 4. Satisfeito & & 5. Muito Satisfeito \\
\hline
\end{tabular}

\subsection{O que influenciou este conceito?}

2. Em se tratando do (s) serviço (s) concluído (s) no (s) mês de maio, classifique o seu grau de satisfação com a qualidade do serviço que você recebeu 
dos técnicos do CME e o grau de importância que deve ser dado na falta deste equipamento durante o tempo de indisponibilidade decorrente da manutenção para o andamento das atividades a serem desenvolvidas por seu Centro de Custo.

\section{Equipamento: APARELHO DE AR CONDICIONADO - Patrimônio №.: 222313}

Ordem de Serviço №.: 4001/2006

GRAU DE SATISFAÇÃO

\begin{tabular}{|l|l|l|l|l|l|l|l|l|l|}
\hline & Muito Insatisfeito & & Insatisfeito & & Indiferente & & Satisfeito & & Muito Satisfeito \\
\hline
\end{tabular}

GRAU DE IMPORTÂNCIA

\begin{tabular}{|l|l|l|l|l|l|l|l|l|l|}
\hline & Nada Importante & & $\begin{array}{l}\text { Pouco } \\
\text { Importante }\end{array}$ & & Indiferente & & Muito Importante & Importantíssimo \\
\hline
\end{tabular}

TEMPO DE RESPOSTA (Tempo entre a sua solicitação do serviço e o primeiro atendimento)

\begin{tabular}{|l|l|l|l|l|l|l|l|l|l|}
\hline & Muito Insatisfeito & & Insatisfeito & & Indiferente & & Satisfeito & & Muito Satisfeito \\
\hline
\end{tabular}

TEMPO DE TOTAL (Tempo entre a sua solicitação do serviço e a conclusão do serviço)

\begin{tabular}{|l|l|l|l|l|l|l|l|l|l|}
\hline & Muito Insatisfeito & & Insatisfeito & & Indiferente & & Satisfeito & & Muito Satisfeito \\
\hline
\end{tabular}

Equipamento: MÁQUINA DE ESCREVER - ELÉTRICA - Patrimônio №.: 152237

Ordem de Serviço №.: 4003/2006

GRAU DE SATISFAÇÃO

\begin{tabular}{|l|l|l|l|l|l|l|l|l|l|}
\hline & Muito Insatisfeito & & Insatisfeito & & Indiferente & & Satisfeito & & Muito Satisfeito \\
\hline
\end{tabular}

GRAU DE IMPORTÂNCIA

\begin{tabular}{|l|l|l|l|l|l|l|l|l|}
\hline & Nada Importante & & $\begin{array}{l}\text { Pouco } \\
\text { Importante }\end{array}$ & & Indiferente & & Muito Importante & Importantíssimo \\
\hline
\end{tabular}

TEMPO DE RESPOSTA (Tempo entre a sua solicitação do serviço e o primeiro atendimento)

\begin{tabular}{|l|l|l|l|l|l|l|l|l|l|}
\hline & Muito Insatisfeito & & Insatisfeito & & Indiferente & & Satisfeito & & Muito Satisfeito \\
\hline
\end{tabular}


TEMPO DE TOTAL (Tempo entre a sua solicitação do serviço e a conclusão do serviço)

\begin{tabular}{|l|l|l|l|l|l|l|l|l|}
\hline & Muito Insatisfeito & & Insatisfeito & & Indiferente & & Satisfeito \\
\hline
\end{tabular}

2.1. O que influenciou este conceito?

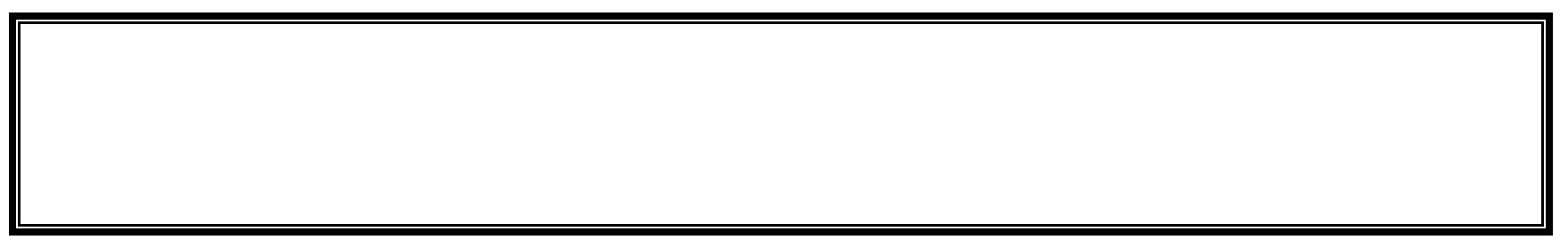

3. Qual o seu julgamento das informações prestadas durante a manutenção dos equipamentos utilizados por você?

\begin{tabular}{|l|l|l|l|l|l|l|l|l|l|}
\hline & Muito Insatisfeito & & Insatisfeito & & Indiferente & & Satisfeito & & Muito Satisfeito \\
\hline
\end{tabular}

4. Qual a sua sugestão para a melhoria do nosso atendimento? 
